\title{
əTeleconnection between the Atlantic Meridional Overturning Circulation and Sea Level in the Mediterranean Sea
}

\author{
DENIS L. VOLKOV \\ Cooperative Institute for Marine and Atmospheric Studies, University of Miami, Coral Gables, and National Oceanic \\ and Atmospheric Administration/Atlantic Oceanographic and Meteorological Laboratory, Miami, Florida \\ MOLLY BARINGER \\ National Oceanic and Atmospheric Administration/Atlantic Oceanographic and Meteorological Laboratory, Miami, Florida \\ DAVID SMEED \\ National Oceanography Centre, Southampton, United Kingdom \\ WILLIAM JOHNS \\ Rosenstiel School of Marine and Atmospheric Science, University of Miami, Miami, Florida \\ FELIX W. LANDERER \\ Jet Propulsion Laboratory, California Institute of Technology, Pasadena, California
}

(Manuscript received 25 July 2018, in final form 11 October 2018)

\begin{abstract}
The Mediterranean Sea can be viewed as a "barometer" of the North Atlantic Ocean, because its sea level responds to oceanic-gyre-scale changes in atmospheric pressure and wind forcing, related to the North Atlantic Oscillation (NAO). The climate of the North Atlantic is influenced by the Atlantic meridional overturning circulation (AMOC) as it transports heat from the South Atlantic toward the subpolar North Atlantic. This study reports on a teleconnection between the AMOC transport measured at $26.5^{\circ} \mathrm{N}$ and the Mediterranean Sea level during 2004-17: a reduced/increased AMOC transport is associated with a higher/lower sea level in the Mediterranean. Processes responsible for this teleconnection are analyzed in detail using available satellite and in situ observations and an atmospheric reanalysis. First, it is shown that on monthly to interannual time scales the AMOC and sea level are both driven by similar NAO-like atmospheric circulation patterns. During a positive/negative NAO state, stronger/weaker trade winds (i) drive northward/southward anomalies of Ekman transport across $26.5^{\circ} \mathrm{N}$ that directly affect the AMOC and (ii) are associated with westward/eastward winds over the Strait of Gibraltar that force water to flow out of/into the Mediterranean Sea and thus change its average sea level. Second, it is demonstrated that interannual changes in the AMOC transport can lead to thermosteric sea level anomalies near the North Atlantic eastern boundary. These anomalies can (i) reach the Strait of Gibraltar and cause sea level changes in the Mediterranean Sea and (ii) represent a mechanism for negative feedback on the AMOC.
\end{abstract}

\section{Introduction}

The Atlantic Ocean is unique for Earth's climate system as it is the only ocean where net heat is transported

¿ Denotes content that is immediately available upon publication as open access.

Corresponding author: Dr. Denis L. Volkov, denis.volkov@ noaa.gov from the Southern Hemisphere across the equator toward the northern subpolar gyre. As the upper warm waters flow northward, they lose heat to the atmosphere, become cooler and denser, and form deep water in the Labrador and Nordic Seas that then returns southward, comprising the Atlantic meridional overturning circulation (AMOC; Fig. 1). The northward heat transport reaches a maximum of $1.3 \mathrm{PW}$ near $24^{\circ}-26^{\circ} \mathrm{N}$ (Hall and Bryden 1982; Trenberth and Caron 2001), with a balanced volume transport between the northward 


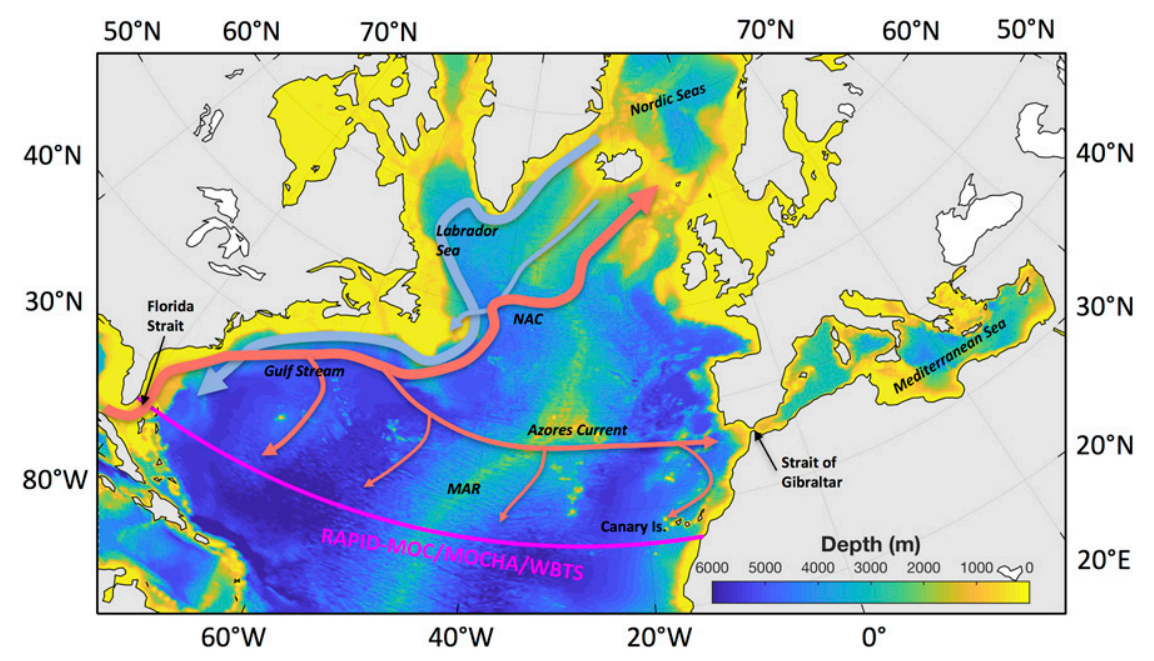

FIG. 1. Bottom topography (color) and schematic representation of the main oceanic flows comprising the meridional overturning circulation (MOC; arrows) in the North Atlantic: pink arrows show the upper-ocean flows and light blue arrows indicate the deep flows. The zonal magenta line indicates the $26.5^{\circ} \mathrm{N}$ MOC monitoring array (RAPID/ MOCHA/WBTS).

flow of warm Gulf Stream waters and wind-driven surface flow (Ekman transport) and the southward flow of cooler thermocline and cold North Atlantic Deep Water. Much of the heat transferred from the ocean to the atmosphere at midlatitudes of the North Atlantic is carried eastward by westerly winds and contributes to the temperate climate of northwest Europe (e.g., Sutton and Hodson 2005). The strength of the westerly winds is strongly associated with the North Atlantic Oscillation (NAO), which is a dominant atmospheric pattern of climate variability over the North Atlantic (Hurrell et al. 2003).

Since 2004, the AMOC has been monitored by an array of moorings deployed along about $26.5^{\circ} \mathrm{N}$ (Cunningham et al. 2007; Johns et al. 2011; Rayner et al. 2011), supplemented by measurements of the Gulf Stream transport using submarine telephone cables in the Straits of Florida (Baringer and Larsen 2001; Fig. 1). It has been documented that changes in the AMOC can affect the sea level around the periphery of the North Atlantic (Levermann et al. 2005), in particular, along the North American east coast (Bingham and Hughes 2009; Ezer et al. 2013; Yin and Goddard 2013; McCarthy et al. 2015b; Little et al. 2017), although they are probably less important than the directly wind-induced variability (Woodworth et al. 2014; Little et al. 2017). In 2009/10, the AMOC temporarily slowed down by $30 \%$, partially due to an extreme negative NAO, when the associated wind field reduced and (for some time) even reversed the northward Ekman transport component of the AMOC
(McCarthy et al. 2012; Srokosz and Bryden 2015). It is possible that this slowdown of the AMOC and the wind anomalies led to an extreme sea level rise along the east coast of North America (Goddard et al. 2015; Andres et al. 2013). In addition, the reduced meridional heat transport caused an upper-ocean cooling in the subtropical Atlantic and warming in the tropics that may have helped push the atmospheric circulation into record-low NAO negative states in both winters of 2009/10 and 2010/11 (Cunningham et al. 2013; Bryden et al. 2014).

Interestingly, on month-to-month time scales, the AMOC transport is negatively correlated with nearly basin-wide variations of sea level in the Mediterranean Sea: a stronger/weaker AMOC is associated with a lower/higher sea level (Figs. 2, 3a). In particular, the observed AMOC slowdown in 2009/10 and then again in winter 2010/11 coincided with the extreme nonseasonal (annual and semiannual signals removed) sea level anomalies in the Mediterranean Sea, reaching amplitudes of about $10 \mathrm{~cm}$ reported in earlier studies (Landerer and Volkov 2013; Volkov and Landerer 2015). These extreme short-term sea level fluctuations have amplitudes larger than approximately $6 \mathrm{~cm}$ of the global mean sea level rise over the last two decades (e.g., Cazenave et al. 2014) and pose a flood threat for coastal communities and infrastructure, as well as a challenge for their understanding and prediction.

As in any semienclosed sea, the Mediterranean Sea level is determined by the local freshwater balance, exchanges with connected basins, and the local variations 


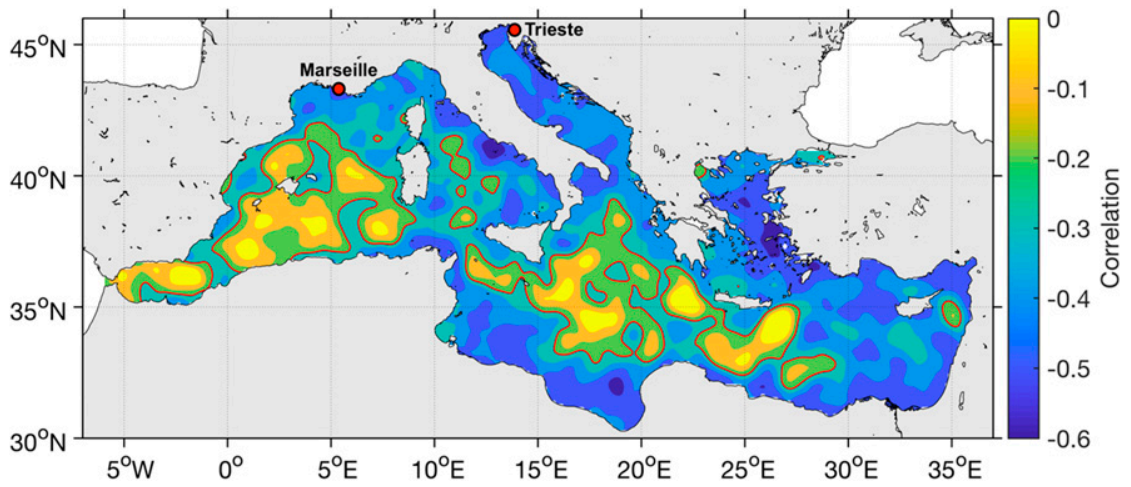

FIG. 2. Correlation between sea level in the Mediterranean Sea and the AMOC transport across $26.5^{\circ} \mathrm{N}$ (monthly unsmoothed values with seasonal cycles removed). The $95 \%$ significance level for correlation $(r=-0.2)$ is shown by the red contour. The locations of Marseille and Trieste tide gauges are shown by red circles.

of depth-integrated seawater density (steric changes). It has been shown that the nonseasonal fluctuations of the Mediterranean Sea level are mainly due to mass exchanges through the Strait of Gibraltar, related to NAO-modulated winds over the strait and the adjacent Atlantic Ocean (Fukumori et al. 2007; Menemenlis et al. 2007; Landerer and Volkov 2013; Calafat et al. 2012; Tsimplis et al. 2013; Volkov and Landerer 2015). An out-of-phase relationship between the nonseasonal bottom pressure fluctuations in the Mediterranean Sea and in the midlatitude North Atlantic has been reported and attributed to large-scale wind stress curl variations and NAO (Piecuch and Ponte 2014). A number of earlier studies have also highlighted the important role of the NAO-modulated sea level pressure, freshwater, and buoyancy fluxes in driving the Mediterranean Sea level (e.g., Tsimplis and Josey 2001; Tsimplis and Rixen 2002; Tsimplis et al. 2005). While the role of NAO in the variability of circulation in the subtropical North Atlantic and the Mediterranean Sea level has been well documented (e.g., Tsimplis and Josey 2001; Tsimplis et al. 2008; Tsimplis and Shaw 2008; Volkov and Fu 2011; Tsimplis et al. 2013; Volkov and Landerer 2015), it is also possible that the large-scale
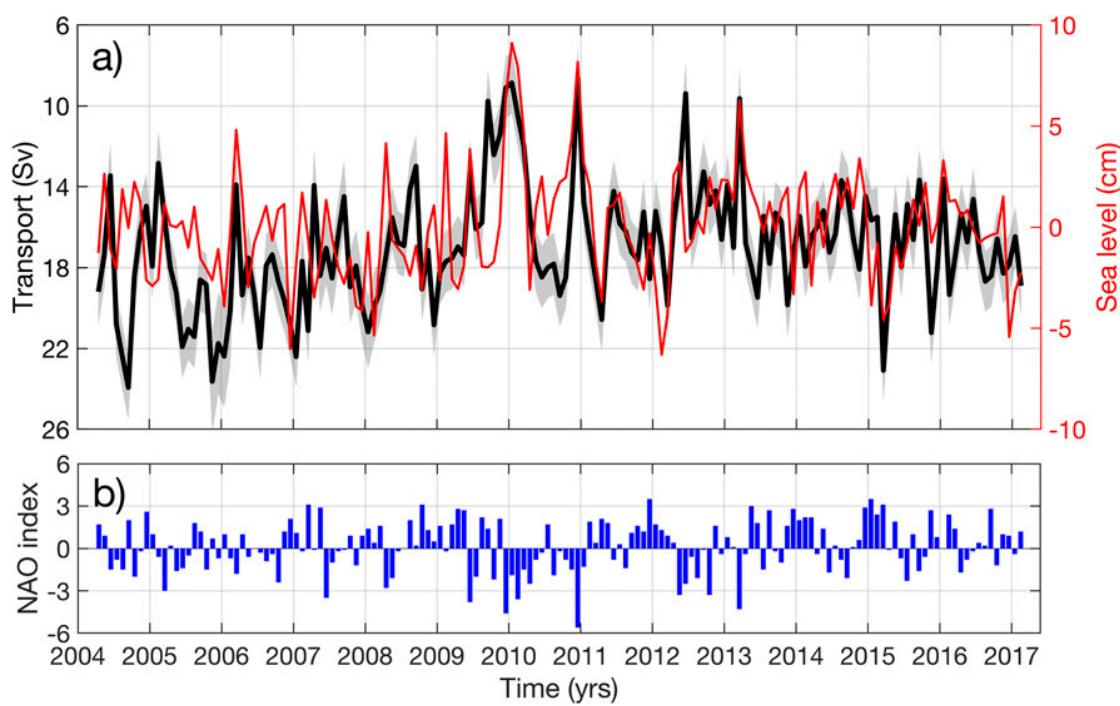

FIG. 3. (a) AMOC transport across $26.5^{\circ} \mathrm{N}$ (black curve) with measurement uncertainty (shaded band) and SLA (global mean sea level and seasonal cycle have been subtracted) averaged over the Mediterranean Sea (red curve). Note that the $y$ axis for the transport is reversed. The correlation between the AMOC and SLA time series is -0.4. (b) Monthly stationbased NAO index. 
ocean circulation in the North Atlantic can impact the Mediterranean Sea level through ocean-atmosphere feedbacks (e.g., Marshall et al. 2001).

The present study adds a novel element to the existing canon in that it reports on the correlation between the AMOC and the Mediterranean Sea level. Although the Mediterranean Sea is an integral part of the North Atlantic air-sea-land coupled climate system, the relationship between sea level in the Mediterranean and the AMOC transport at $26.5^{\circ} \mathrm{N}$ has not yet been established and explored. It is not clear why the two remote and probably not directly related processes are correlated. Are the AMOC and sea level in the Mediterranean simply forced by the same processes, such as the $\mathrm{NAO}$ ? Or does the AMOC provide a forcing that directly and/or indirectly affects sea level in the Mediterranean? In this study, we use satellite altimetry observations of sea surface height, measurements of the meridional transports across $26.5^{\circ} \mathrm{N}$, temperature and salinity fields and profiles, and an atmospheric reanalysis to reveal and document the dynamical mechanisms that linked the AMOC and the Mediterranean Sea level in 2004-17.

The manuscript is organized as follows. In sections 2 and 3 , we describe the data used in this work and data analysis methods, respectively. Section 4 reports on the observed correlations between the AMOC transport components, the Mediterranean Sea level, and the NAO. In sections 5 and 6 , we explore the dynamical mechanisms responsible for the observed correlations. Finally, section 7 provides summary and discussion.

\section{Data}

\section{a. Sea level measurements}

For sea level, we used both the regional (Mediterranean Sea) and global monthly maps of sea level anomalies (SLAs) for the time period from January 1993 to February 2017, processed and distributed by the Copernicus Marine and Environment Monitoring Service (CMEMS; http://marine.copernicus.eu). The SLA maps are generated by merging measurements by up to four altimetry satellites using all missions available at a given time. Prior to mapping, the along-track altimetry records are routinely corrected for instrumental noise, orbit determination error, atmospheric refraction, sea state bias, static and dynamic atmospheric pressure effects, and tides (Pujol et al. 2016). The global mean sea level has been subtracted from the SLA time series at each grid point to focus on local dynamic fluctuations not related to global changes. The area-weighted average time series represents the Mediterranean basinwide SLA (SLA MS $)$.
Satellite altimetry data were supplemented with monthly tide gauge measurements at Marseille, France, from 1900 to 2010 and Trieste, Italy, from 1927 to 2010, obtained from the Permanent Service for Mean Sea Level (www.psmsl.org). These are the longest records available in the Mediterranean, dating back to the end of the nineteenth century, but the records at Trieste prior to 1927 have substantial (multiyear) gaps. Shorter-term gaps at Marseille were either filled by linear interpolation prior to 1993 or by altimetry data after 1993. The tide gauge records were corrected for the inverted barometer (IB) effect given by IB $=\left(P_{\text {ref }}-P_{a}\right) /(\rho g)$, where $P_{a}$ is the sea level pressure (SLP), and $P_{\text {ref }}$ is the SLP averaged over the entire ocean, $\rho$ is the seawater density, and $g$ is gravity.

\section{b. Observations of $A M O C$ at $26.5^{\circ} \mathrm{N}$}

Monitoring the AMOC at $26.5^{\circ} \mathrm{N}$ has been carried out since 2004 under the auspices of the RAPID-MOCHAWestern Boundary Time Series [WBTS (RAPID)] program (Smeed et al. 2017). Key measurements are collected at the western and eastern boundaries of the Atlantic Ocean at $26.5^{\circ} \mathrm{N}$ and on either side of the MidAtlantic Ridge (MAR). Because of the sloping boundaries, several moorings at different locations and depths on the slope are combined to form a single profile as described in McCarthy et al. (2015a). The resulting time series of temperature and salinity profiles at the boundaries are used to derive dynamic height anomaly profiles from which the midocean meridional geostrophic transport is calculated.

An estimate of the AMOC transport ( $\left.T_{\text {AMOC }}\right)$ is obtained as the sum of (i) the upper-midocean transport ( $\left.T_{\mathrm{UMO}}\right)$ down to the deepest northward velocity at $\sim 1100 \mathrm{~m}$ (Johns et al. 2005), (ii) the Florida Current transport $\left(T_{\mathrm{FC}}\right)$ obtained by measuring the voltage difference across the Straits of Florida using submarine telephone cables (Baringer and Larsen 2001), and (iii) the near-surface meridional Ekman transport $\left(T_{\mathrm{EK}}\right)$ estimated using the zonal wind stress from the European Centre for Medium-Range Weather Forecasts (ECMWF) ERA-Interim reanalysis (McCarthy et al. 2015a): $T_{\mathrm{AMOC}}=$ $T_{\mathrm{FC}}+T_{\mathrm{EK}}+T_{\mathrm{UMO}}$. The lower limb of the overturning (deep southward flow) is represented by the sum of the upper North Atlantic Deep Water (NADW) transport ( $T_{\mathrm{UNADW}} ; 1100-3000 \mathrm{~m}$ ) and lower NADW transport $\left(T_{\mathrm{LNADW}} ; 3000-5000 \mathrm{~m}\right)$, so that $T_{\mathrm{AMOC}} \approx-\left(T_{\mathrm{UNADW}}+\right.$ $\left.T_{\text {LNADW }}\right)$ (Cunningham et al. 2007).

Here, we use both the 12-hourly time series of the meridional transports across $26.5^{\circ} \mathrm{N}$ and the 12 -hourly vertical profiles of temperature and salinity near the eastern and western boundaries from April 2004 to February 2017 provided by RAPID. The meridional 
heat transport is derived from the RAPID observing system as described in Johns et al. (2011). Temperature and salinity profiles are used to compute dynamic height anomalies. Because most of the RAPID moorings have the shallowest measurements in the 100-200-dbar-depth range, the dynamic height profiles were extended up to the surface using a cubic extrapolation (McCarthy et al. 2015a). The time series of meridional transports and dynamic height anomalies were averaged monthly, thus yielding 155 monthly estimates.

\section{c. Temperature and salinity data}

The monthly gridded temperature and salinity profiles from January 2004 to February 2017, produced by the Japan Agency for Marine-Earth Science and Technology (JAMSTEC) from all available data including (and mostly) Argo (Hosoda et al. 2008), are used to compute the contribution to sea level variability in the North Atlantic from changes in density (the steric component):

$$
\operatorname{SLA}_{s t}=-\rho_{0}^{-1} \int_{-H}^{0} \rho^{\prime}(T, S, z) d z
$$

where $\rho^{\prime}$ is an in situ density anomaly with respect to the time mean, $\rho_{0}=1027.5 \mathrm{~kg} \mathrm{~m}^{-3}, T$ is temperature, $S$ is salinity, $z$ is depth, and $H$ is the reference depth for the integration. Because we focus on the upper limb of overturning (upper $1100 \mathrm{~m}$ ), the steric sea level anomalies were referenced to 1100-m depth. The steric sea level anomalies $\left(\mathrm{SLA}_{s t}\right)$ can be approximately (because of nonlinearity of the equation of state) decomposed into the thermosteric SLA $\left(\mathrm{SLA}_{t}\right)$ and halosteric SLA $\left(\mathrm{SLA}_{s}\right)$ components:

$$
\begin{aligned}
\operatorname{SLA}_{s t} \approx & \operatorname{SLA}_{t}+\operatorname{SLA}_{s}=-\rho_{0}^{-1}\left[\int_{-H}^{0} \rho^{\prime}(T, \bar{S}, z) d z\right. \\
& \left.+\int_{-H}^{0} \rho^{\prime}(\bar{T}, S, z) d z\right]
\end{aligned}
$$

where the overbar indicates the time-mean values.

\section{d. Atmospheric and reanalysis data}

To link the observed changes in the ocean to atmospheric forcing, we used the monthly mean fields of SLP, net surface heat flux $\left(Q_{\text {net }}\right)$, wind stress, 10-m wind speed, and sea surface temperature (SST) for the 19792017 time period provided by the ECMWF's ERAInterim reanalysis project (Dee et al. 2011). The long tide gauge records at Marseille and Trieste were compared to $T_{\mathrm{EK}}$ at $26.5^{\circ} \mathrm{N}$ estimated from the ECMWF's Twentieth Century Analysis (ERA-20C) over the 19002010 time interval (Poli et al. 2013). In addition, we used the monthly station-based NAO index, based on the difference of normalized SLP between Lisbon, Portugal, and Reykjavík, Iceland, and provided by the Climate Analysis Section of the National Center for Atmospheric Research (NCAR; Hurrell et al. 2003).

\section{Methods}

The seasonal cycle was computed by fitting the annual and semiannual harmonics in a least squares sense and removed from all fields and time series. Wavelet coherence (Grinsted et al. 2004) is used to find regions in time-frequency space where SLA $A_{\mathrm{MS}}$ and $T_{\mathrm{EK}}$ covary (Fig. 4). Linear regression is used to examine the spatial patterns of SLP and wind changes with reference to the AMOC and Mediterranean Sea level variability: the monthly fields of SLP, zonal, and meridional 10-m wind velocities are projected onto the monthly $T_{\mathrm{AMOC}}$ and SLA $_{M S}$ time series (e.g., Fig. 6). The corresponding regression coefficients are in pascals per Sverdrup (Sv; $1 \mathrm{~Sv} \equiv 10^{6} \mathrm{~m}^{3} \mathrm{~s}^{-1}$ ) for $T_{\mathrm{AMOC}}$ and meters per second per centimeter for SLA MS $_{\text {(local changes in SLP and wind }}$ speed with respect to changes in the AMOC transport and Mediterranean Sea level, respectively).

To focus on the interannual variability, the monthly time series were further smoothed with a "Lowess" filter with a 24-month span (approximately equivalent to a moving average with a 1-yr window). An empirical orthogonal function (EOF) analysis (von Storch and Zwiers 1999) was used to identify the leading EOF mode (EOF-1) of the interannual sea level variability in the North Atlantic (Fig. 9). The spatial pattern of EOF-1 is represented as a regression map obtained by projecting the sea level data onto the standardized (divided by standard deviation) principal component [PC (PC-1)] time series. Thus, the regression coefficients are in centimeters (local change of sea level) per standard deviation change of PC-1.

The $95 \%$ significance level for correlation coefficients was estimated by computing correlations between the pairs of 10000 Monte Carlo simulations of random time series that have the same autocorrelation functions as the observed time series. For the nonseasonal monthly time series with 155 data points, the $95 \%$ significance level for correlation is about 0.2. For the smoothed time series (interannual signal), the $95 \%$ significance level for correlation is about 0.5 at zero lag and 0.6 at 12 -month lag.

The net surface heat flux and temperature advection by ocean currents drive the thermosteric sea level variability,

$$
\frac{\partial \mathrm{SLA}_{t}}{\partial t}=-\alpha\left(\frac{Q_{\mathrm{net}}-\bar{Q}_{\mathrm{net}}}{\rho_{0} C_{p}}+\int_{-H}^{0} \mathbf{u} \cdot \nabla T d z\right),
$$

where $\alpha$ is the thermal expansion coefficient, $C_{p}$ is the specific heat capacity of seawater, $\bar{Q}_{\text {net }}$ is the climatological 

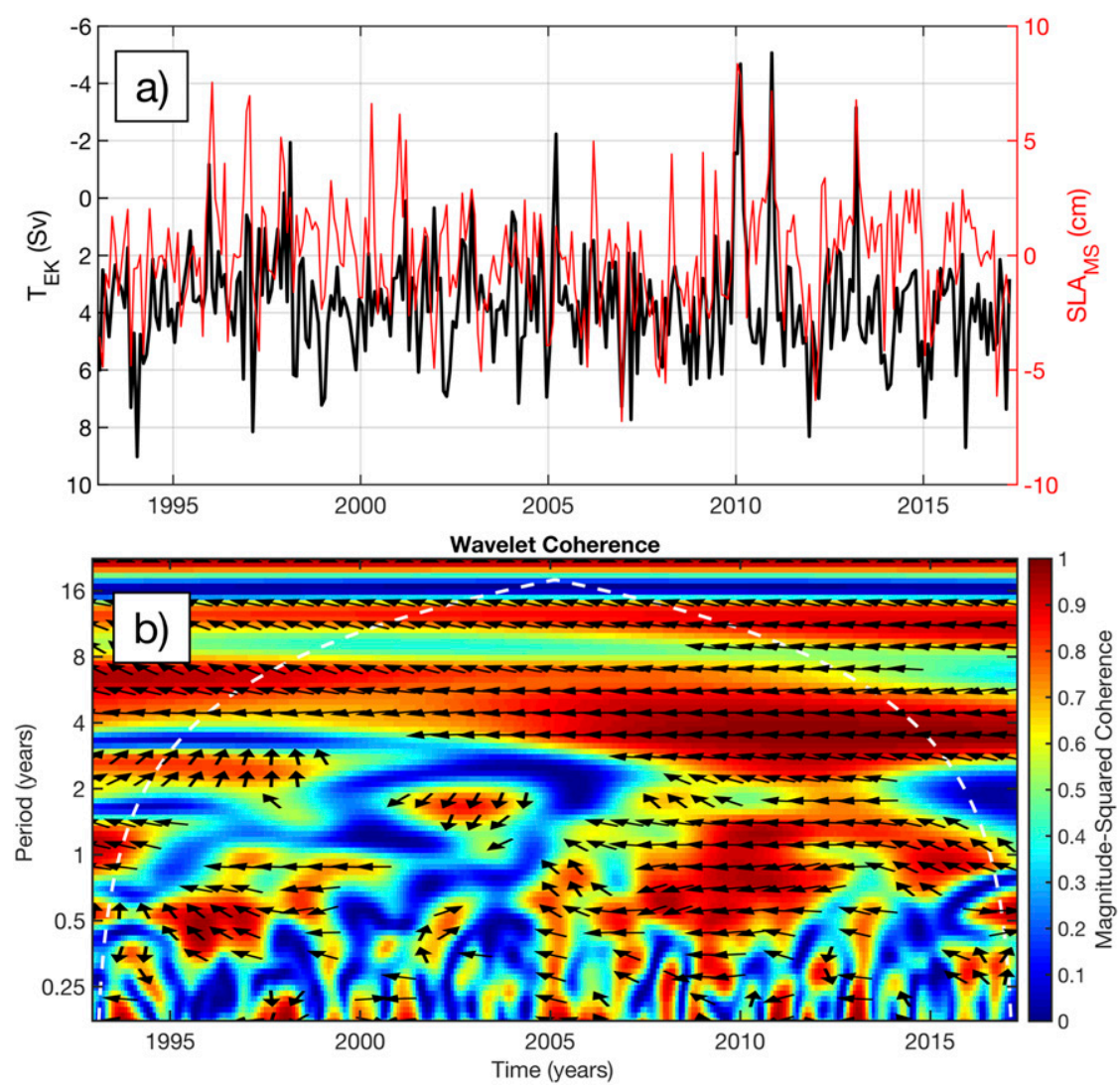

FIG. 4. (a) The monthly time series of SLA $\mathrm{MS}_{\mathrm{MS}}$ from satellite altimetry and $T_{\mathrm{EK}}$ at $26.5^{\circ} \mathrm{N}$ computed from the ERA-Interim zonal wind stress and (b) the wavelet coherence between the time series in (a). Note that the $y$ axis for $T_{\mathrm{EK}}$ is reversed. The direction of the arrows in the coherence plot corresponds to the phase lag on the unit circle, with the backward direction indicating an out-of-phase relationship. The cone of influence in the coherence plot (whitedashed curve) indicates where edge effects occur in the coherence data.

(averaged over 2004-17) net surface heat flux (positive fluxes are directed out of the ocean), and $\mathbf{u}$ is the ocean current velocity. We estimated the first term on the right side of Eq. (3) using the ERA-Interim fields of $Q_{\text {net }}$. The spatially variable thermal expansion coefficient was computed from the JAMSTEC fields of temperature and salinity and averaged over the upper $100 \mathrm{~m}$. The second (advection) term is largely unknown. However, by assuming the ageostrophic component is well characterized by Ekman transport, the contribution of temperature advection by Ekman transport can be approximated using a pseudo air-sea heat flux following Marshall et al. (2001):

$$
H_{\mathrm{Ek}}=C_{p}\left(-\mathbf{k} \times \frac{\boldsymbol{\tau}}{f}\right) \cdot \nabla \mathrm{SST},
$$

where $\mathbf{k}$ is the unit vector in the vertical, $\boldsymbol{\tau}$ is the wind stress, $f$ is the Coriolis parameter, and SST is the sea surface temperature, which is used as an approximation of the upper Ekman layer temperature. For consistency with surface fluxes, we used the ERA-Interim wind stress and SST. Then, assuming that the vertical heat advection is small, the thermosteric sea level change of the upper $1100 \mathrm{~m}$ water column becomes

$$
\begin{aligned}
\frac{\partial \mathrm{SLA}_{t}}{\partial t} \approx & -\alpha\left(\frac{Q_{\mathrm{net}}-\bar{Q}_{\mathrm{net}}}{\rho_{0} C_{p}}+\frac{H_{\mathrm{Ek}}-\bar{H}_{\mathrm{Ek}}}{\rho_{0} C_{p}}\right. \\
& \left.+\int_{1100 \mathrm{~m}}^{0} \mathbf{u}_{\text {geos }} \cdot \nabla T d z\right),
\end{aligned}
$$

where $\mathbf{u}_{\text {geos }}$ is the geostrophic velocity. In this study, we are able to directly estimate only the first two terms on the right side of Eq. (5).

\section{Observed correlations}

\section{a. Monthly variability}

Displayed in Fig. 3a are the monthly time series of the nonseasonal SLA $\mathrm{MS}_{\mathrm{MS}}$ and $T_{\mathrm{AMOC}}$ at $26.5^{\circ} \mathrm{N}$. The zero-lag 


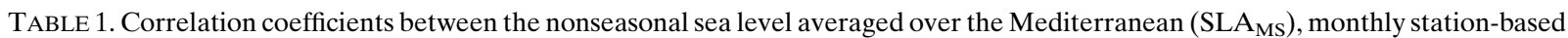
NAO indices, and meridional transports across $26.5^{\circ} \mathrm{N}: T_{\mathrm{AMOC}}, T_{\mathrm{FC}}, T_{\mathrm{EK}}, T_{\mathrm{UMO}}, T_{\mathrm{UNADW}}$, and $T_{\mathrm{LNADw}}$. Correlation coefficients between the time series, from which interannual signals have been removed, are shown in brackets. The $95 \%$ significance level for correlation is about 0.2 .

\begin{tabular}{|c|c|c|c|c|c|c|c|}
\hline & SLA $_{M S}$ & $T_{\text {AMOC }}$ & $T_{\mathrm{FC}}$ & $T_{\mathrm{EK}}$ & $T_{\mathrm{UMO}}$ & $T_{\text {UNADW }}$ & $T_{\text {LNADW }}$ \\
\hline $\mathrm{SLA}_{\mathrm{MS}}$ & - & $-0.40(-0.44)$ & $-0.18(-0.21)$ & $-0.52(-0.53)$ & $0.04(-0.02)$ & $-0.01(0.00)$ & $0.46(0.50)$ \\
\hline$T_{\text {AMOC }}$ & - & - & $0.44(0.44)$ & $0.57(0.54)$ & $0.42(0.51)$ & $-0.50(-0.48)$ & $-0.89(-0.91)$ \\
\hline NAO & $-0.48(-0.48)$ & $0.43(0.39)$ & $0.13(0.12)$ & $0.77(0.78)$ & $-0.15(-0.15)$ & $-0.12(-0.09)$ & $-0.42(-0.39)$ \\
\hline
\end{tabular}

correlation between them is -0.4 , which is significant at $95 \%$ confidence (Table 1). The weaker-than-average AMOC transport is associated with the higher-thanaverage $\mathrm{SLA}_{\mathrm{MS}}$. This is particularly valid for the extremely large anomalies in both the AMOC and SLA observed in 2009/10. A strong decrease of the AMOC from about $21 \mathrm{~Sv}$ in December 2008 to about $9 \mathrm{~Sv}$ in January 2010 and then again in December 2010 was accompanied by the record-high sea level anomalies of above $8 \mathrm{~cm}$ in the Mediterranean Sea. This happened when the NAO index also became strongly negative (Fig. 3b). Similar events associated with the negative NAO, but with smaller changes in $T_{\mathrm{AMOC}}$ and SLA $\mathrm{MS}$, were repeated in 2012 and 2013.

As already mentioned, the correlation between the Mediterranean Sea level and $T_{\mathrm{AMOC}}$ is nearly basin wide across the Mediterranean, except for some interior regions (Fig. 2). It appears that the correlation is significant mainly because of high inverse correlation between $\mathrm{SLA}_{\mathrm{MS}}$ and Ekman transport at $26.5^{\circ} \mathrm{N}(r=-0.52$; Table 1): the positive (northward) anomalies of $T_{\mathrm{EK}}$ are associated with the negative anomalies of SLA MS $_{\text {and }}$ vice versa. The variability of $T_{\mathrm{EK}}$ at $26.5^{\circ} \mathrm{N}$ is part of the large-scale variability in winds over the North Atlantic. This large-scale variability is modulated by the NAO, which explains the high correlation $(r=0.77)$ between the monthly $T_{\mathrm{EK}}$ and NAO indices (Table 1). Probably due to its connection with $T_{\mathrm{EK}}$, the NAO is significantly correlated with $T_{\mathrm{AMOC}}(r=0.43)$, which for the longer time scales has been reported earlier (e.g., Stepanov and Haines 2014; Delworth and Zeng 2016).

To investigate whether the observed relationship between SLA $\mathrm{MS}_{\text {and }} T_{\mathrm{EK}}$ in 2004-17 holds for prior periods, we compared (i) the satellite altimetry record of SLA ${ }_{\mathrm{MS}}$ to $T_{\mathrm{EK}}$ from ERA-Interim in 1993-2017 and (ii) the tide gauge records at Marseille (1900-2010) and Trieste (1927-2010) to $T_{\mathrm{EK}}$ from ERA-20C (19002010). The correlation between the monthly time series of SLA $\mathrm{MS}_{\mathrm{MS}}$ and $T_{\mathrm{EK}}$ is -0.43 (Fig. $4 \mathrm{a}$ ). The wavelet coherence (Fig. 4b) shows that the relationship is nonstationary but is time and frequency dependent. The relationship between SLA $A_{\mathrm{MS}}$ and $T_{\mathrm{EK}}$ becomes stronger after 2005, when the time series covary at most frequencies. The time series covary out of phase, which is demonstrated by the predominantly left-oriented arrows. The correlation between the longer tide gauge records and $T_{\mathrm{EK}}$ (not shown) is -0.21 for Marseille and -0.22 for Trieste, significant at $95 \%$ confidence. The reduction of correlation coefficient is due to the longer time series (more degrees of freedom), limited representativeness of Marseille and Trieste tide gauge records for the basin-averaged Mediterranean Sea level (correlation between the tide gauge records and altimetry SLA $\mathrm{MS}_{\mathrm{M}}$ in 1993-2017 is 0.6 for Marseille and 0.8 for Trieste), and also because the uncertainties in Ekman transport computed from the ERA-20C reanalysis are larger for presatellite era (prior to 1979) than for satellite era.

The other components of the AMOC, $T_{\mathrm{FC}}$ and $T_{\mathrm{UMO}}$,

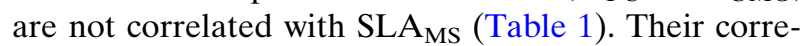
lation with $T_{\mathrm{AMOC}}$ is also smaller $(0.44$ and 0.42 , respectively) than correlation between $T_{\mathrm{EK}}$ and $T_{\mathrm{AMOC}}$ (0.57). Therefore, at nonseasonal month-to-month time scales, wind stress appears to be the main driver of the AMOC variability at $26.5^{\circ} \mathrm{N}$. We find that both $T_{\text {UNADW }}$ and $T_{\text {LNADw }}$ are also significantly correlated with the $\operatorname{AMOC}(r=-0.50$ and -0.89 , respectively; Table 1$)$, which is expected because the northward $T_{\text {AMOC }}$ is compensated by the total southward North Atlantic Deep Water transport. However, $T_{\text {UNADw }}$ is not correlated with $\operatorname{SLA}_{\mathrm{MS}}(r=-0.01)$, whereas $T_{\mathrm{LNADW}}$ is positively correlated with $\mathrm{SLA}_{\mathrm{MS}}(r=0.46$; Table 1$)$. We recall that the midocean meridional transports provided by RAPID include the (unmeasured) compensating flow that ensures a net zero meridional volume transport (McCarthy et al. 2015a). It appears that the correlation between $T_{\mathrm{LNADW}}$ and $\mathrm{SLA}_{\mathrm{MS}}$ is primarily due to this compensating transport. If the compensating transport is subtracted from $T_{\mathrm{LNADW}}$, then the correlation between $\mathrm{SLA}_{\mathrm{MS}}$ and $T_{\mathrm{LNADW}}$ becomes -0.21 . Since the LNADW layer lies just above the reference level (4820 dbar), then it is the most sensitive to changes in the compensating transport and is strongly influenced by it, whereas farther up in the water column there tends to be more cancellation between the shear-related transport changes and the opposing barotropic changes. Although 


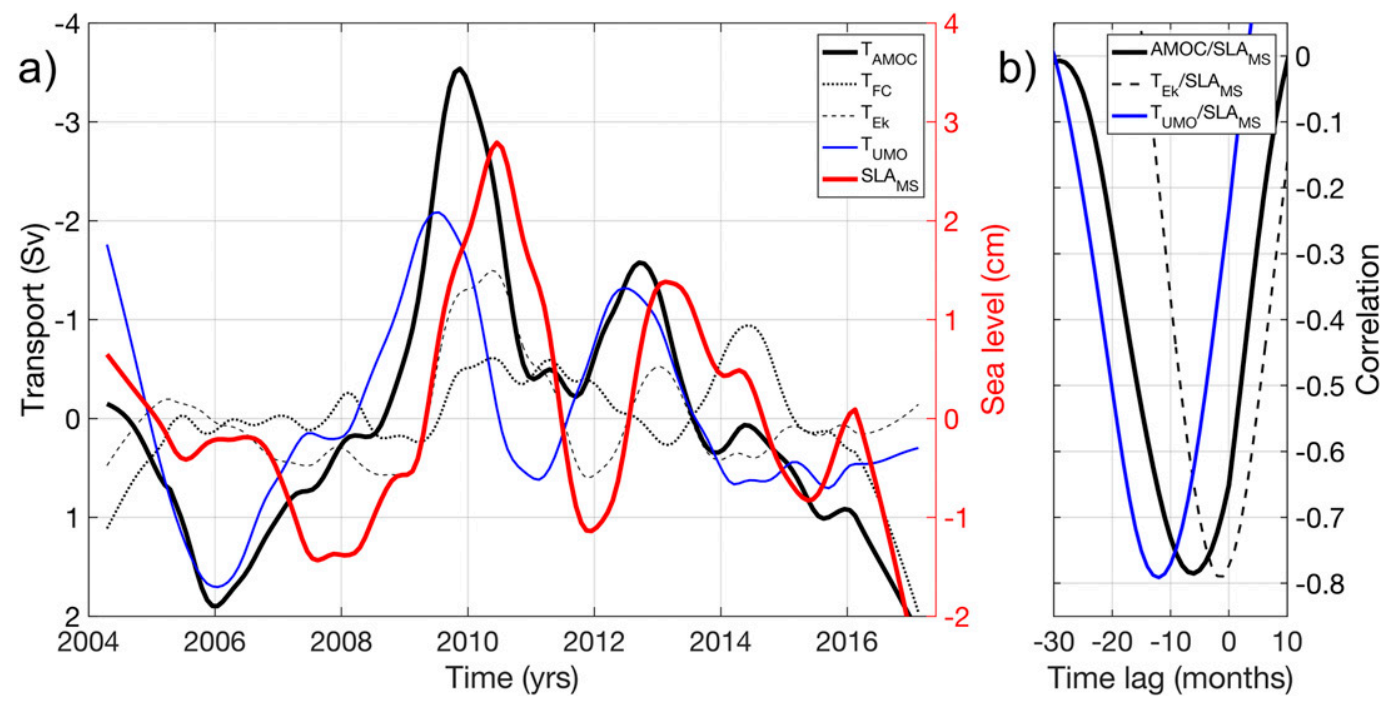

FIG. 5. (a) The smoothed time series of $\mathrm{SLA}_{\mathrm{MS}}$ (red) and the AMOC transport components: $T_{\mathrm{AMOC}}$ (black), $T_{\mathrm{FC}}$ (dotted black), $T_{\mathrm{EK}}$ (dashed black), and $T_{\mathrm{UMO}}$ (blue). Note that the $y$ axis for the transport is reversed. (b) Crosscorrelation functions of SLA $\mathrm{MS}_{\mathrm{MS}}$ and $T_{\mathrm{AMOC}}$ (black), SLA ${ }_{\mathrm{MS}}$ and $T_{\mathrm{EK}}$ (dotted black), and SLA $\mathrm{MS}_{\mathrm{US}}$ and $T_{\mathrm{UMO}}$ (blue). All time series were detrended.

$T_{\text {LNADW }}$ from RAPID contains the unmeasured compensating transport, it is well correlated with an independent estimate of $T_{\text {LNADW }}$ derived solely from satellite time-variable gravity measurements (Landerer et al. 2015), meaning that the RAPID estimate is robust. Note that since a substantial part of the barotropic compensation is balancing Ekman transport variations, there is also a relatively high correlation between $T_{\mathrm{EK}}$ and $T_{\text {LNADw }}(-0.59$; Frajka-Williams et al. 2016).

\section{b. Interannual variability}

It should be noted that removing interannual signals from the time series does not significantly affect the observed correlations (Table 1), suggesting that the zero-lag relationships are dominated by month-tomonth fluctuations. However, in addition to these month-to-month variations, there are lagged correlations between the interannual signals of SLA $\mathrm{S}_{\mathrm{MS}}$ and meridional transports at $26.5^{\circ} \mathrm{N}$ (Fig. 5; Table 2). The maximum correlation between $T_{\mathrm{AMOC}}$ and $\mathrm{SLA}_{\mathrm{MS}}$ is -0.78 , with SLA $_{\mathrm{MS}}$ lagging behind $T_{\mathrm{AMOC}}$ by six months (Fig. 5b). It has been reported earlier that the Ekman component plays a dominant role in the AMOC variability on short time scales and the geostrophic component, represented mainly by $T_{\mathrm{UMO}}$, becomes more important on interannual time scales (e.g., Buckley and Marshall 2016). On these interannual time scales, we find that $T_{\mathrm{UMO}}$ is highly correlated with the Mediterranean Sea level: the correlation between $T_{\mathrm{UMO}}$ and SLA ${ }_{M S}$ reaches a maximum of -0.79 when the latter lags behind the former by 12 months (Fig. 5b). This relationship suggests that the Mediterranean Sea level may respond to baroclinic changes in the subtropical North Atlantic, and in the remainder of the manuscript, we will try to unveil the mechanisms that link these two remote processes. The correlation between $T_{\mathrm{EK}}$ and $\mathrm{SLA}_{\mathrm{MS}}$ on interannual time scales is also significant $(r=-0.79)$ at 1 -month time lag, and it is mainly due to the large anomalies in 2010 and in 2012/ 13 (Fig. 5a).

\section{Wind forcing as a common driver}

We have demonstrated that the correlation between

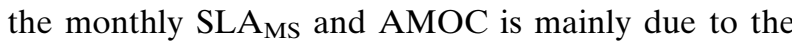
relationship between these quantities and the atmospheric forcing that is expressed through the local Ekman transport at $26.5^{\circ} \mathrm{N}$ and through the gyre-scale NAO. To reveal the atmospheric circulation patterns that contribute to the variability of the AMOC and $\mathrm{SLA}_{\mathrm{MS}}$, here we present the regression of the monthly

TABLE 2. Maximum lagged correlation coefficients and time lags between the low-pass filtered (interannual) SLA MS $_{\text {and meridional }}$ transports across $26.5^{\circ} \mathrm{N}$ (as shown in Fig. 5b): $T_{\mathrm{AMOC}}, T_{\mathrm{EK}}$, and $T_{\text {UMO }}$. The $95 \%$ significance level for correlation is 0.5 at zero lag and 0.6 at 12 -month lag.

\begin{tabular}{lcc}
\hline \hline & SLA $_{\mathrm{MS}}$ & Lag (months) \\
\hline$T_{\mathrm{AMOC}}$ & -0.78 & 6 \\
$T_{\mathrm{EK}}$ & -0.79 & 1 \\
$T_{\mathrm{UMO}}$ & -0.79 & 12 \\
\hline
\end{tabular}



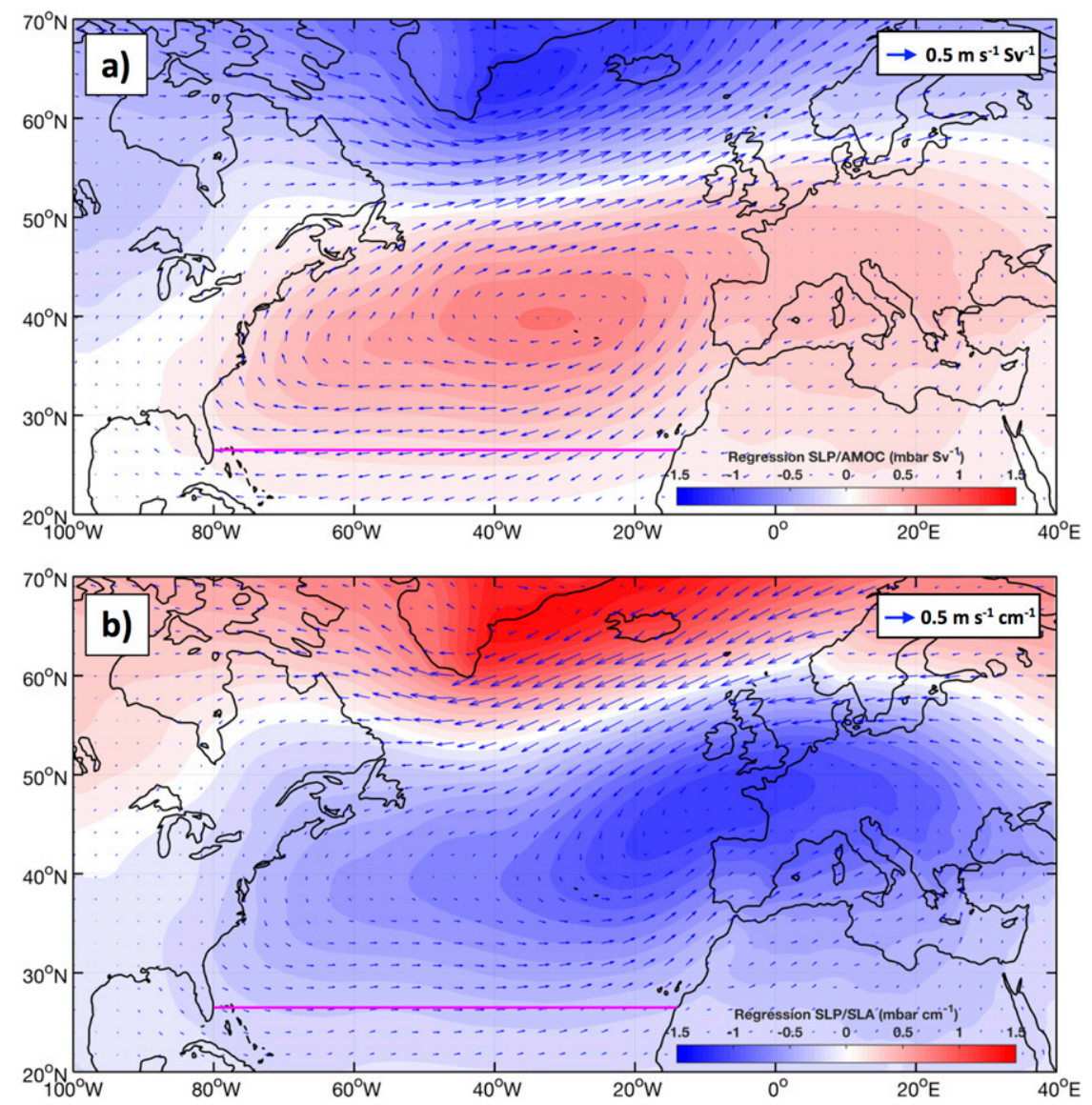

FIG. 6. The regression maps of monthly SLP and $10-\mathrm{m}$ wind velocity from ERA-Interim projected on (a) the AMOC transport across $26.5^{\circ} \mathrm{N}$ and (b) sea level in the Mediterranean Sea at zero lag (monthly unsmoothed values with seasonal cycles removed).

ERA-Interim SLP and 10-m wind velocity fields on the AMOC and on SLA ${ }_{M S}$ time series (seasonal cycles removed). It appears that both the AMOC and SLA $\mathrm{AS}_{\mathrm{MS}}$ are related to similar dipole SLP patterns reminiscent of NAO, with one pressure center located at midlatitude (the Azores high) and the other at high-latitude North Atlantic (the Icelandic low; Fig. 6). This suggests that the AMOC and SLA $\mathrm{MS}_{\mathrm{S}}$ are both driven, at least partially, by the same mode of the large-scale atmospheric variability. It is interesting to note, however, that the subtropical lobe of the pattern in Fig. $6 \mathrm{~b}$ is centered more toward the eastern part of the ocean and over western Europe than in Fig. 6a.

As expected, the spatial pattern of regression between SLP and AMOC (Fig. 6a) is mostly determined by regression between SLP and $T_{\mathrm{EK}}$ (not shown). An increase/decrease of SLP at midlatitudes $\left(\sim 40^{\circ} \mathrm{N}\right)$ is associated with a strengthening/weakening of the North Atlantic westerly and trade winds. The stronger/ weaker trade winds in the subtropics around $26.5^{\circ} \mathrm{N}$ drive the northward/southward near-surface Ekman transport anomalies and, thus, directly impact the AMOC. An increase/decrease of SLP by about $0.8 \mathrm{mb}$ around $40^{\circ} \mathrm{N}$, $35^{\circ} \mathrm{W}$ is associated with a $1 \mathrm{~Sv}$ increase/decrease in the AMOC transport. The other AMOC constituents $\left(T_{\mathrm{FC}}\right.$ and $\left.T_{\mathrm{UMO}}\right)$ are not significantly related to SLP changes in the North Atlantic (not shown), however, ultimately, their variability is in part the result of how the ocean thermohaline structure and circulation adjust to the varying atmospheric forcing.

The month-to-month variability of SLA $\mathrm{MS}_{\mathrm{S}}$ is mostly driven by winds over the Strait of Gibraltar and just west of it (Landerer and Volkov 2013). This is essentially a basin-wide barotropic response to the along-strait wind setup that forces water into or out of the Mediterranean Sea until the zonal sea level pressure gradient balances the wind stress (Fukumori et al. 2007; Menemenlis et al. 2007). Because these winds are part of the North Atlantic large-scale atmospheric circulation, it is not surprising that $\mathrm{SLA}_{\mathrm{MS}}$ is related to an NAO-like dipole SLP and associated atmospheric circulation patterns (Fig. 6b). An increase/decrease of SLP by about $1 \mathrm{mb}$ 

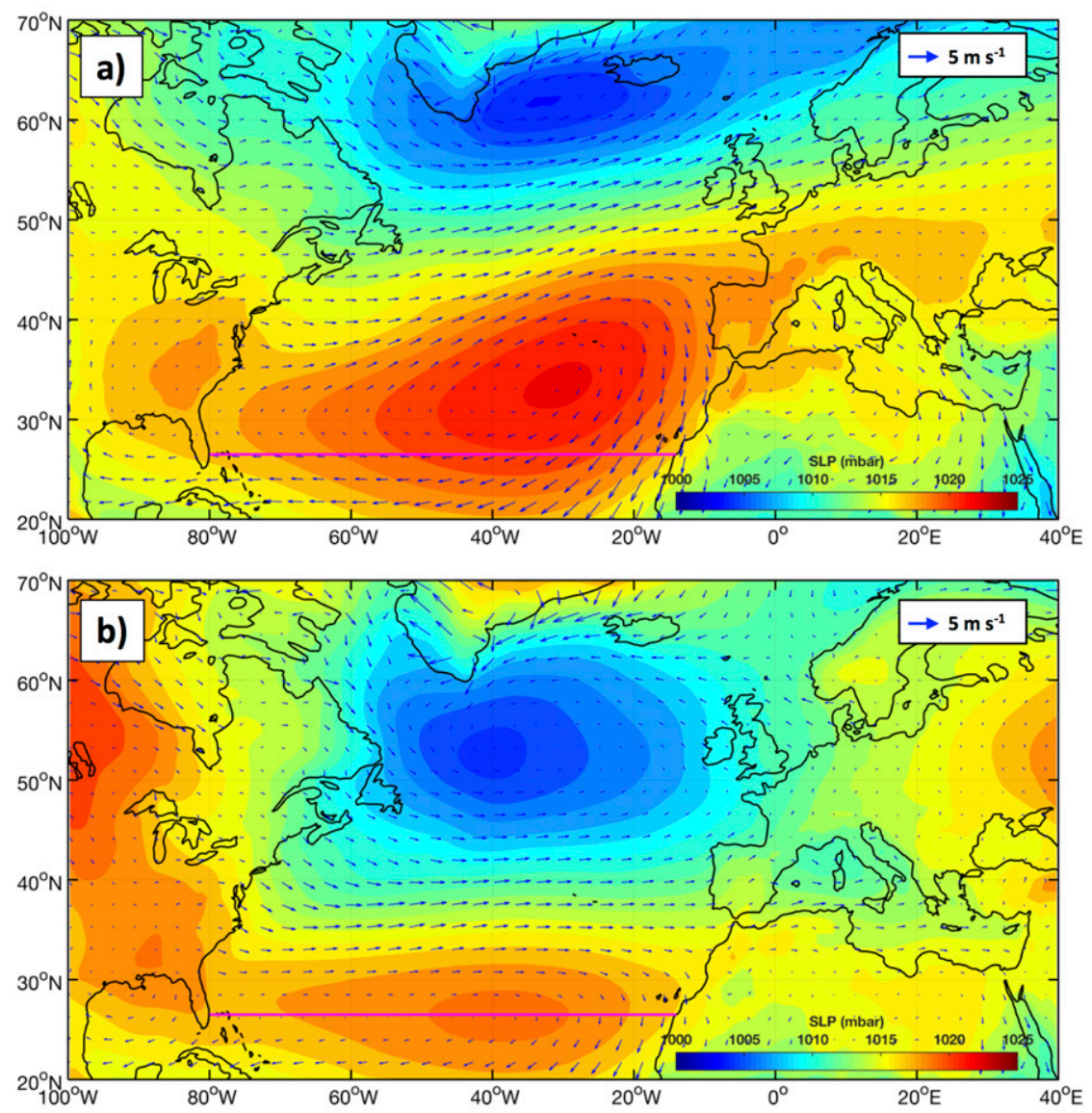

FIG. 7. SLP (color) and 10-m wind velocity (arrows) for (a) 1979-2017 mean climatology and (b) composite for the periods when SLA $\mathrm{MS} \geq 4 \mathrm{~cm}$ over the Mediterranean Sea (see Fig. 3a).

around $45^{\circ} \mathrm{N}, 15^{\circ} \mathrm{W}$ is associated with northeastward/ southwestward wind anomalies along the northwest African coast and eastward/westward wind anomalies across the Strait of Gibraltar that force water to flow into/out of the Mediterranean Sea and, thus, raise/lower its level surface by about $1 \mathrm{~cm}$.

It is instructive to explore the atmospheric SLP and circulation pattern during the observed record-high Mediterranean Sea level and record-low AMOC in 2009-11 and in 2013 relative to the 1979-2015 SLP and wind climatology (Fig. 7a). For this, we present a composite map of SLP and $10-\mathrm{m}$ wind velocity for the periods when SLA $_{M S}$ (shown in Fig. 3a) was greater than $4 \mathrm{~cm}$ (Fig. 7b). During these periods, the Greenland anticyclone strengthened and expanded, while the subtropical and subpolar SLP centers became weaker and shifted southward by about $10^{\circ}$. These changes were associated with a southward shift of westerly and trade winds. The westerly winds became more zonal and centered near the latitude of the Strait of Gibraltar $\left(\sim 35^{\circ} \mathrm{N}\right)$, which led to stronger westerly winds over the strait itself that pumped water into the Mediterranean Sea and raised its sea level. At the same time, the usually northward Ekman transport at $26.5^{\circ} \mathrm{N}$ (directed $90^{\circ}$ to the right of the wind direction in the Northern Hemisphere) weakened to almost zero (it can occasionally reverse, as seen in Fig. 4a) and, therefore, reduced the AMOC transport.

\section{Dynamic connection with the large-scale North Atlantic circulation}

\section{a. Relation to sea level in the eastern North Atlantic}

Using an ocean general circulation model, Calafat et al. (2012) showed that on decadal time scales, sea level at the Atlantic side of Gibraltar is correlated with sea level along the northwest coast of Africa. The authors suggested that the long-shore wind forcing drives the coastal sea level variability, which by the means of coastally trapped waves propagates toward the Strait of Gibraltar and ultimately translates to basin-wide 

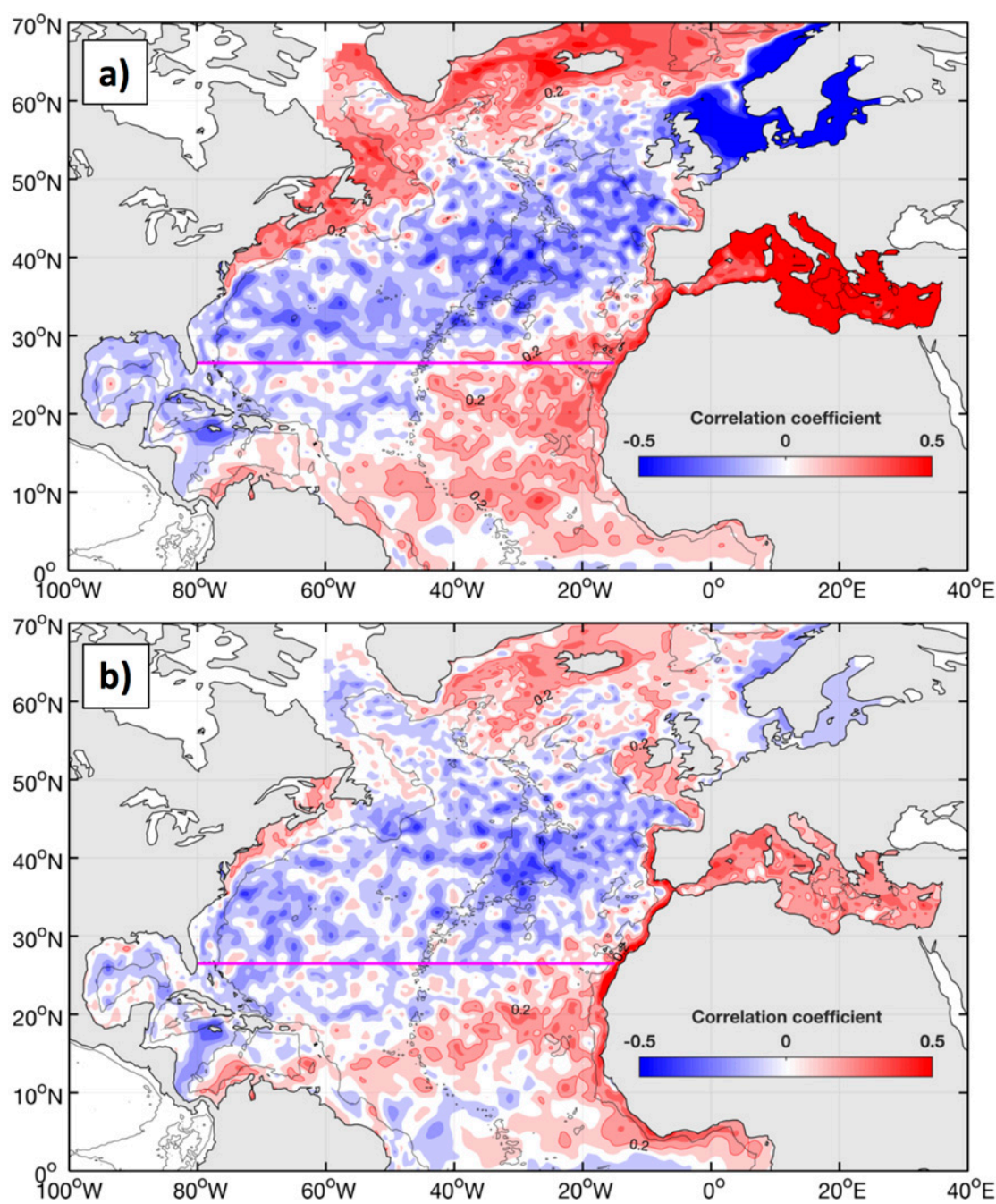

FIG. 8. Correlation maps for (a) correlation between the monthly (unsmoothed) sea level averaged over the Mediterranean and satellite altimetry SLA in the North Atlantic and (b) correlation between the monthly (unsmoothed) dynamic height from the eastern boundary moorings and satellite altimetry SLA in the North Atlantic. The $95 \%$ significance level is \pm 0.2 ; the positive (negative) significance level is shown by red (cyan) contours.

changes of sea level in the Mediterranean. Here, we utilize this concept to understand the mechanism that links the North Atlantic large-scale geostrophic circulation and the Mediterranean Sea level.

Displayed in Fig. 8 are the correlation maps between the monthly (unsmoothed) SLA MS $_{\text {and SLA (Fig. 8a) }}$ and the monthly (unsmoothed) dynamic height at the eastern boundary from RAPID moorings and SLA (Fig. 8b). Despite minor differences, the two maps exhibit similar patterns, probably related to large-scale baroclinic processes as suggested by the correlation with the dynamic height. The correlation pattern is also consistent with the gyre-scale atmospheric circulation. When there is a cyclonic circulation anomaly in the subtropical North Atlantic (similar to the pattern in Fig. 6b, associated with a positive sea level anomaly in the Mediterranean) the upper-ocean Ekman transport anomaly near the eastern boundary is directed onshore and, therefore, it tends to reduce the coastal upwelling typical for this region, deepen the thermocline, and, thus, produce a positive steric sea level anomaly along the African coast. In addition, the anomaly pattern shown in Fig. 6b causes an anticyclonic (negative) wind stress curl anomaly along the eastern part of the RAPID line at $26.5^{\circ} \mathrm{N}$, which leads to additional Ekman pumping and higher dynamic height.

In agreement with Calafat et al. (2012), there is a band of high correlation along the northwest African coast 

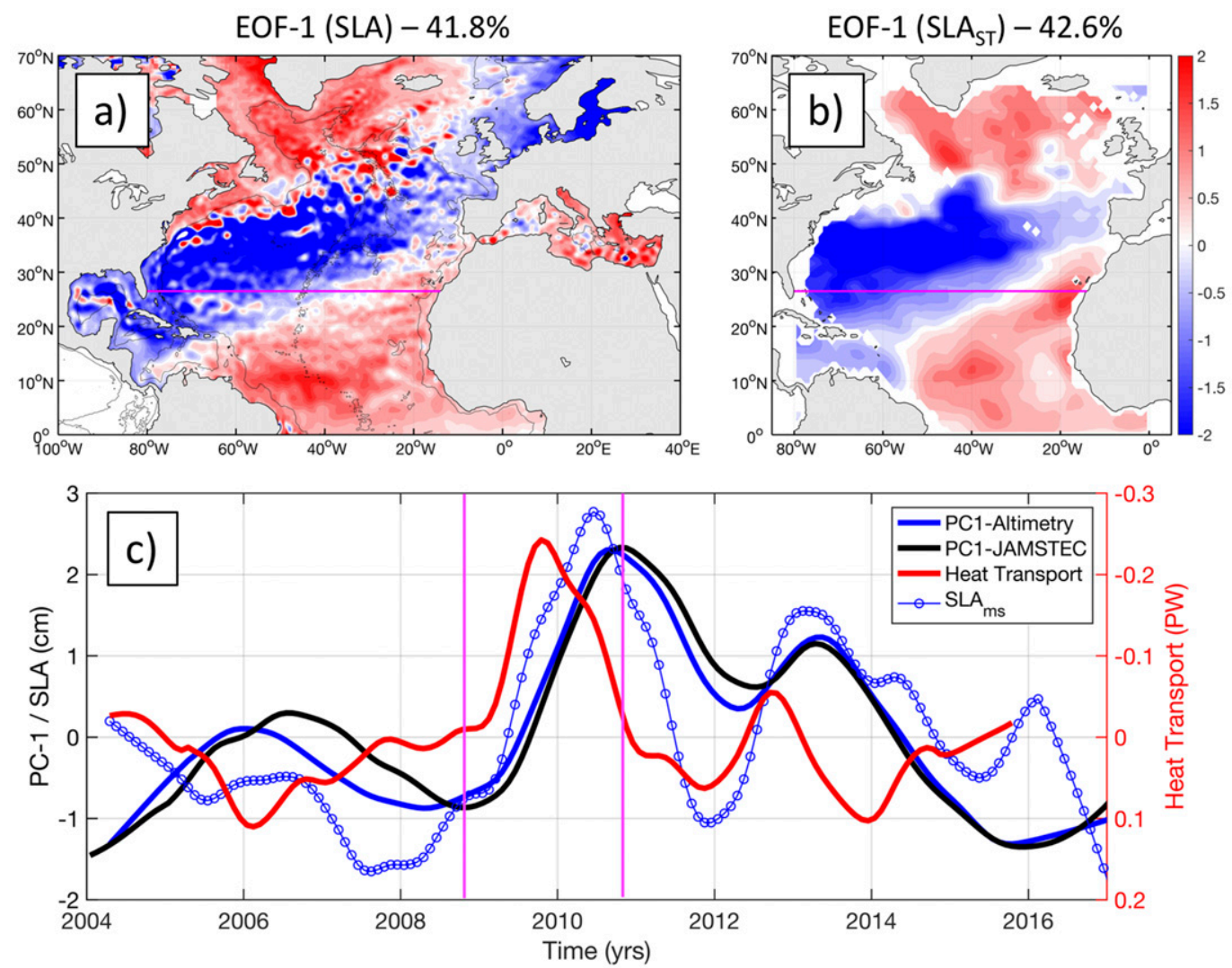

FIG. 9. The first empirical mode of sea level variability for the spatial patterns of EOF-1 of (a) SLA from satellite altimetry and (b) SLA ST $_{\text {from JAMSTEC data and (c) the time evolution (PC) of EOF-1 for SLA (blue) and SLA }}$ (red). In (c), the blue curve with circles shows SLA $_{M S}$ and the red curve shows the meridional heat transport across $26.5^{\circ} \mathrm{N}$ (note that $y$ axis for heat transport is reversed). The vertical magenta lines in (c) mark October 2008 and October 2010, when sea level in the equatorial-tropical band was at a local minimum and the record-high maximum, respectively.

toward the Strait of Gibraltar (Fig. 8). The correlation between the dynamic height from RAPID moorings and local SLA is about 0.6. The shallowest RAPID mooring near the eastern boundary sits at 1000-m depth and about $50 \mathrm{~km}$ offshore. High correlation between the dynamic height computed from the mooring data and coastal sea level from altimetry (Fig. 8b) suggests that the latter can be partially controlled by baroclinic processes in the deep ocean. The existence of coastally trapped waves means that whenever the sea level becomes high at a certain location near the coast, it also becomes high farther poleward because of propagation (Gill 1982). If we consider the characteristic poleward propagation speed of about $2 \mathrm{~cm} \mathrm{~s}^{-1}$ (for the first baroclinic mode; Smith 1978), it takes about eight days for the sea level signal to propagate from $26.5^{\circ} \mathrm{N}$ to the Strait of Gibraltar. This explains why, at the time scales considered in this study, monthly sea level anomalies along the African coast and in the Mediterranean Sea appear to be synchronous. A rather broad area of significant positive correlation in the tropical
North Atlantic indicates that the coastal sea level is coupled to the sea level over the deep ocean. Therefore, the Mediterranean Sea level is also linked to baroclinic changes in the North Atlantic that can be related to the upper-ocean geostrophic circulation.

\section{b. Tripole mode of sea level variability in the North Atlantic}

It appears that the correlation pattern in Fig. 8 is related to the first mode of the interannual sea level variability, as illustrated by the first EOF of the low-pass filtered (with a cutoff period of one year) SLA (Fig. 9a) and $\operatorname{SLA}_{s t}$ (Fig. 9b), explaining $41.8 \%$ and $42.6 \%$ of the variance, respectively. Because the mass contribution to the interannual sea level variability is apparently small, the two independent observing systems (satellite altimetry and Argo) show very similar spatial (Figs. 9a,b) and temporal (Fig. 9c) patterns. The EOF-1 manifests a tripole pattern of the large-scale interannual sea level variability: the midlatitude band, stretching from the 
Caribbean to Europe and associated with the Gulf Stream and the North Atlantic Current (NAC), varies out of phase with both the equatorial-tropical band including the Mediterranean and the subpolar North Atlantic. The temporal evolution of EOF-1 is well correlated $(r=0.79)$ with SLA $_{M S}$ in 2006-15 (Fig. 9c) meaning that at least during this time interval the basinaveraged sea level in the Mediterranean was part of the large-scale sea level variability in the North Atlantic.

Interestingly, the RAPID section at $26.5^{\circ} \mathrm{N}$ lies exactly across the boundary between the midlatitude and equatorial-tropical bands of the tripole sea level variability pattern. The western part of the section is within the midlatitude band, while the eastern part of the section crosses the northeastward extension of the equatorial-tropical band, meaning that there is a zonal sea level gradient associated with EOF-1. This provides a direct link to the AMOC, because the $T_{\mathrm{UMO}}$ at $26.5^{\circ} \mathrm{N}$ is related to the zonal difference in pressure and sea level between the eastern and western boundaries of the North Atlantic (e.g., Frajka-Williams 2015). We recall that $T_{\mathrm{UMO}}$ and SLA $_{M S}$, which is characteristic for the eastern boundary sea level, are not in phase (Fig. 5a) and on average there is a 12-month time lag (Fig. 5b; Table 2). The periods of the low sea level at the eastern boundary in winters 2007/08 and 2011/12 were followed by strengthening of the southward upper-midocean transport. And then, as the southward $T_{\mathrm{UMO}}$ reached maximum values in 2009 and 2012, the sea level at the eastern boundary and in the Mediterranean was increasing until it reached peak values in 2010 and 2013 (Figs. 5a, 9c).

The time-mean profiles of temperature (Fig. 10a) and salinity (Fig. 10c) averaged between $10^{\circ}$ and $40^{\circ} \mathrm{W}$ provide a possible explanation of why the southward/ northward anomalies of $T_{\mathrm{UMO}}$ and the AMOC are associated with increasing/decreasing sea level in the equatorial-tropical/midlatitude bands. Both the temperature and salinity profiles display a downward domeshaped structure centered at $30^{\circ}-35^{\circ} \mathrm{N}$ and associated with the midlatitude band. Because the meridional temperature and salinity gradients (contours in Figs. 9a,c) south of the dome are predominantly positive, the time-mean $T_{\mathrm{UMO}}$ (southward) advects heat and salt from the midlatitude band to the equatorial-tropical band. Hence, the southward/northward anomalies of $T_{\mathrm{UMO}}$ can lead to heat and salt convergence/divergence in the equatorial-tropical band. It has been shown earlier that this process drives the subsurface temperature variability in the tropical North Atlantic (Wang and Zhang 2013).

It is instructive to compare the thermohaline structures in October 2008 and October 2010, when the sea level in the equatorial-tropical band was at low and maximum values, respectively (Fig. 9c). The differences of temperature (Fig. 10b) and salinity (Fig. 10d) between October 2010 and October 2008 clearly show the upper-ocean cooling and freshening in the midlatitude band and warming and salinification in the equatorialtropical band. The temperature (salinity) increase exceeded $1^{\circ} \mathrm{C}(0.1 \mathrm{psu})$ in the upper $100 \mathrm{~m}$ and $0.2^{\circ} \mathrm{C}(0.02$ psu) at a depth of $500 \mathrm{~m}$. The maximum increase of temperature and salinity in the tropics was centered at $20^{\circ} \mathrm{N}$. The fact that temperature and salinity changes are not limited to the mixed layer indicates an important role of geostrophic advection in driving these changes.

At $26.5^{\circ} \mathrm{N}$, the upper-midocean transport is correlated with the meridional heat transport (cf. Fig. 5a and Fig. 9c) derived from the RAPID/MOCHA/WBTS observing system (Johns et al. 2011). Apparently, the interannual variability of the AMOC and associated meridional heat transport is linked to the tripole mode of sea level variability in the North Atlantic. The negative (southward) heat transport anomalies in 2009 and 2012 were followed by the positive anomalies of heat content and, therefore, steric sea level in the equatorial-tropical band (Fig. 9c), consistent with Cunningham et al. (2013) and Bryden et al. (2014) analyses. This provides further evidence that a reduction of the AMOC, associated with the strengthening of the southward $T_{\mathrm{UMO}}$, can lead to heat convergence in the equatorial-tropical band and, consequently, rising sea levels along the northwest coast of Africa and ultimately in the Mediterranean Sea.

\section{c. Mechanisms driving the thermosteric sea level change in 2008-10}

We have shown that the difference in the thermohaline structure between October 2010 and October 2008 appears to be mechanistically related to the meridional advection of heat and freshwater. Changes in the thermohaline structure are in turn linked to changes in the steric sea level. The sea level change from October 2008 to October 2010 (Fig. 11a) was mostly accounted for by the steric sea level change (Fig. 11b). The differences between Figs. $11 \mathrm{a}$ and $11 \mathrm{~b}$ are largely due to the differences in the spatial resolution and sampling of satellite altimetry and Argo measurements. The thermosteric component (Fig. 11c) determines the sign of the steric sea level change, but it is partly offset by the halosteric sea level change (Fig. 11d). In agreement with temperature and salinity profiles (Figs. 10b,d), the maximum thermosteric and halosteric sea level change is centered at about $20^{\circ} \mathrm{N}$ and concentrated in the eastern part of the tropical North Atlantic. The maximum thermosteric sea level change near the eastern boundary exceeds $8 \mathrm{~cm}$ and about $50 \%$ of this change is compensated by the halosteric component.

Because the thermosteric component (Fig. 12a, as in Fig. 11c) determines the sign of the sea level change near 

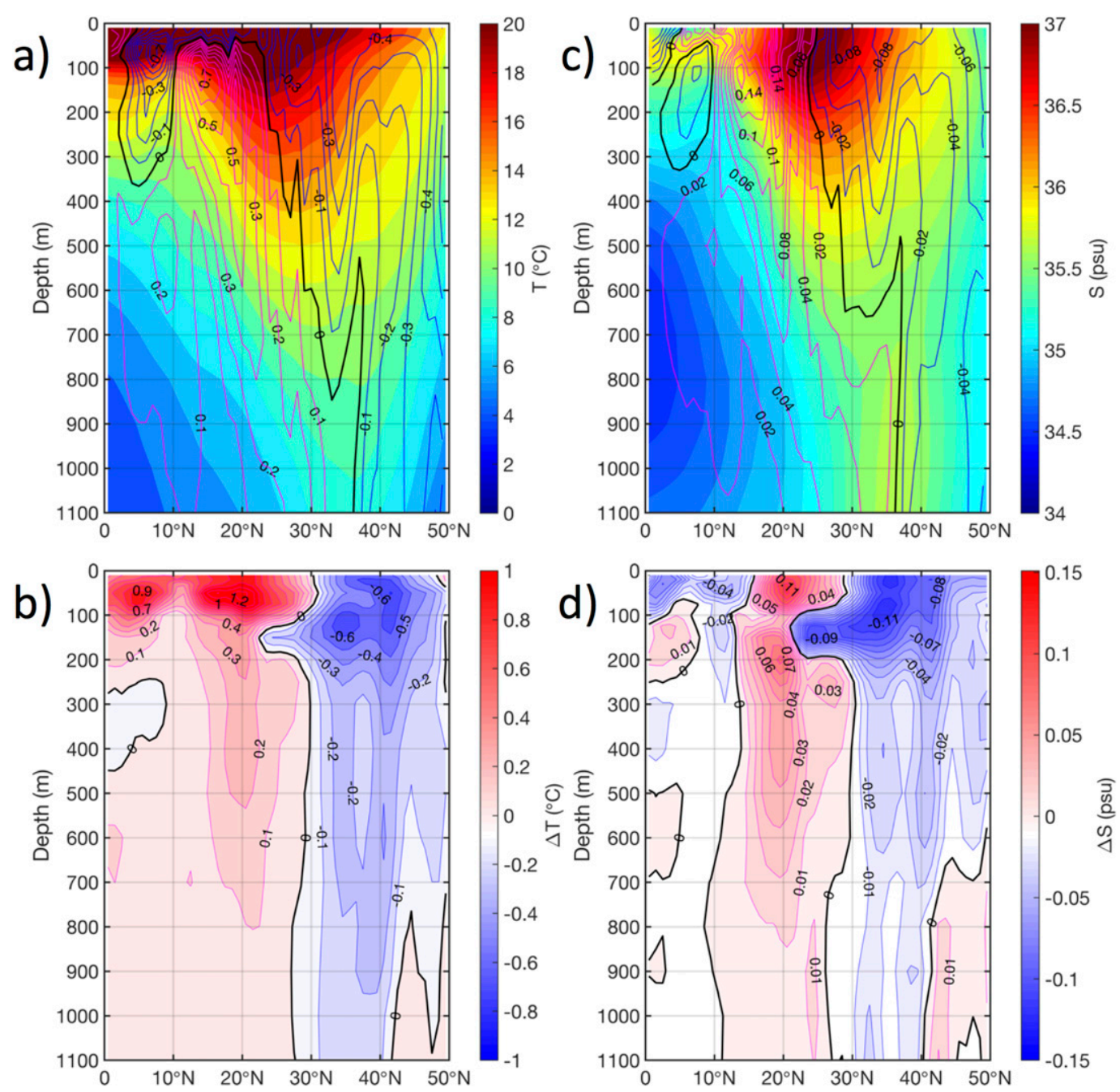

FIG. 10. The JAMSTEC time-mean profiles of (a) temperature and (c) salinity (color) averaged between $10^{\circ}$ and $40^{\circ} \mathrm{W}$, with the meridional gradients (contours) of temperature $\left[{ }^{\circ} \mathrm{C}(100 \mathrm{~km})^{-1}\right.$ ] and salinity [psu $(100 \mathrm{~km})^{-1}$ ] gradients, respectively. The differences of the low-pass filtered (b) temperature and (d) salinity profiles between October 2010 (high sea level near the eastern boundary) and October 2008 (low sea level near the eastern boundary).

the eastern boundary of the North Atlantic, we further analyze what mechanisms caused the thermosteric sea level change in the region. According to Eq. (3), the thermosteric sea level variability is driven by the net surface heat flux and heat advection by ocean currents. Between October 2008 and October 2010, the net surface heat flux anomaly was negative, that is, warming the ocean and raising the thermosteric sea level, over about a $10^{\circ}-15^{\circ}$ tropical band centered at about $20^{\circ} \mathrm{N}$ (Fig. 12b). The magnitude of the thermosteric sea level change due to the net surface heat flux was amplified in the eastern part of the basin and reached about $2 \mathrm{~cm}$, while the total thermosteric sea level change reached $6-8 \mathrm{~cm}$. Clearly, the net surface heat flux does not fully explain the observed thermosteric sea level change in the region and, therefore, the remaining amount of heat had to be advected by ocean currents. It should be noted that the thermosteric sea level change due to $Q_{\text {net }}$ [in Eqs. (3) and (5)] is somewhat sensitive to the period over which the mean climatology $\bar{Q}_{\text {net }}$ was computed. Nevertheless, we found that using longer periods, for example, 2000-17 (satellite era) and 1979-2017 (including presatellite era), does not impact the conclusions. Furthermore, when these periods are used, the contribution of $Q_{\text {net }}$ is even smaller compared to using the 2004-17 climatology.

We are not able to directly calculate the contribution of heat advection because of the lack of velocity data, 

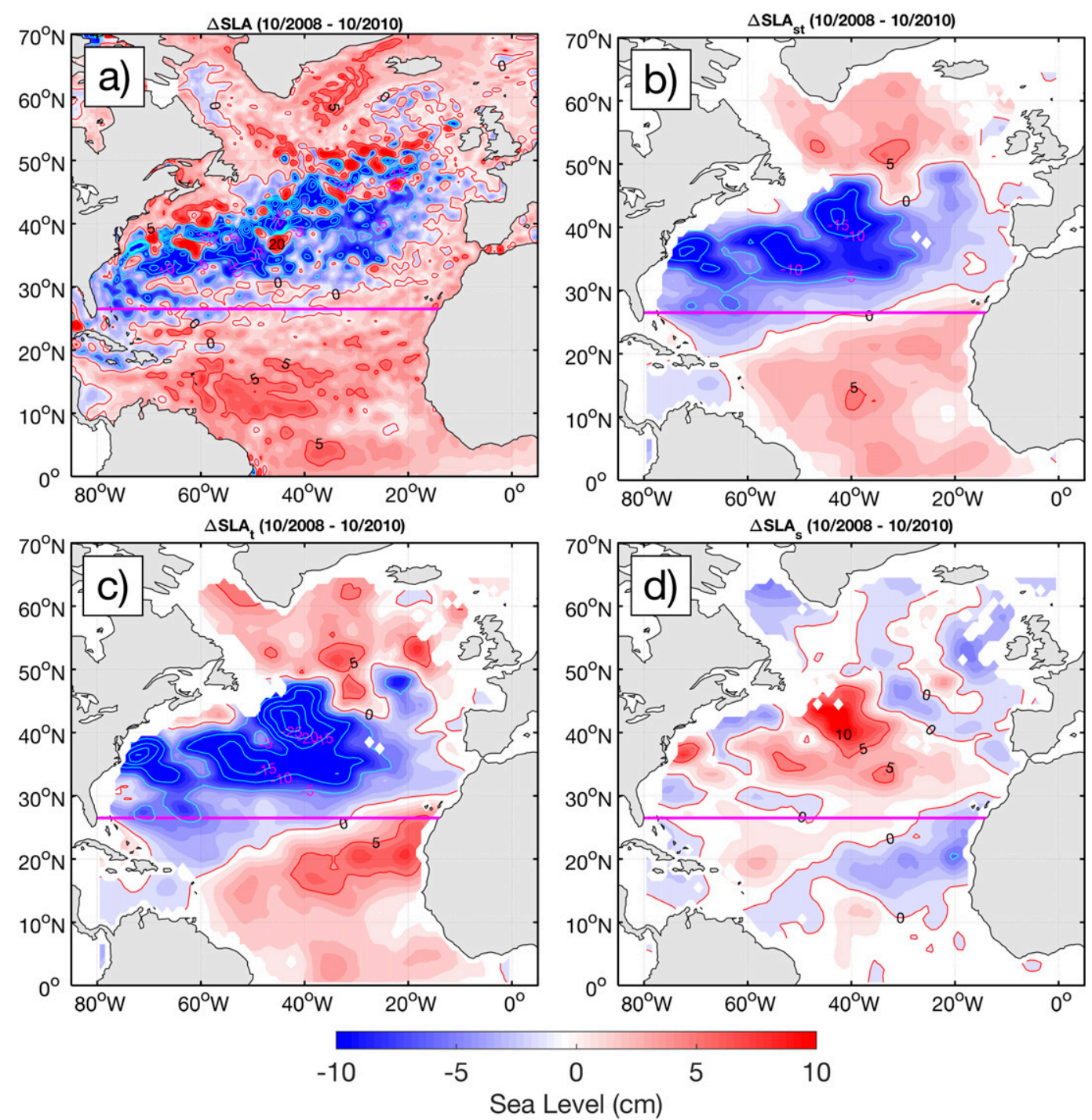

FIG. 11. Processes responsible for the sea level change from October 2008 to October 2010 for (a) the total sea level change observed by satellite altimetry, (b) the steric sea level change derived from JAMSTEC gridded product, (c) the thermosteric sea level change, and (d) the halosteric sea level change.

but using a pseudo air-sea heat flux given by Eq. (4), we can evaluate the role of the near-surface advection by Ekman currents (Fig. 12c). Over the ocean interior, the contribution of Ekman advection to the thermosteric sea level change in $2008-10$ is fairly small and hardly exceeds $1 \mathrm{~cm}$ in the tropics and midlatitudes. However, in the vicinity of the eastern boundary between $20^{\circ}$ and $26^{\circ} \mathrm{N}$, the Ekman advection becomes important and its contribution increases up to $4 \mathrm{~cm}$ toward the African coast. This agrees with Calafat et al. (2012), who demonstrated the important role of heat advection by Ekman currents in the coastal sea level changes south of $25^{\circ} \mathrm{N}$. Complementary to their result, we note that in 2008-10, the Ekman heat advection near the African coast was also accompanied by a larger-scale geostrophic heat advection into the equatorial-tropical band of the North Atlantic, which was also associated with the coastal sea level rise. This result appears to be not sensitive to the climatology of $H_{\mathrm{Ek}}$ [Eq. (5)].

The advection of heat by geostrophic currents [the last term in Eq. (5)] in 2008-10 can be estimated indirectly as the residual of the thermosteric sea level change (Fig. 12a) after subtracting the contributions of the net surface heat flux (Fig. 12b) and Ekman advection (Fig. 12c). The uncertainty of this estimate is unknown, and it arises from the uncertainties in Argo and ERA-Interim data products. Keeping in mind the 

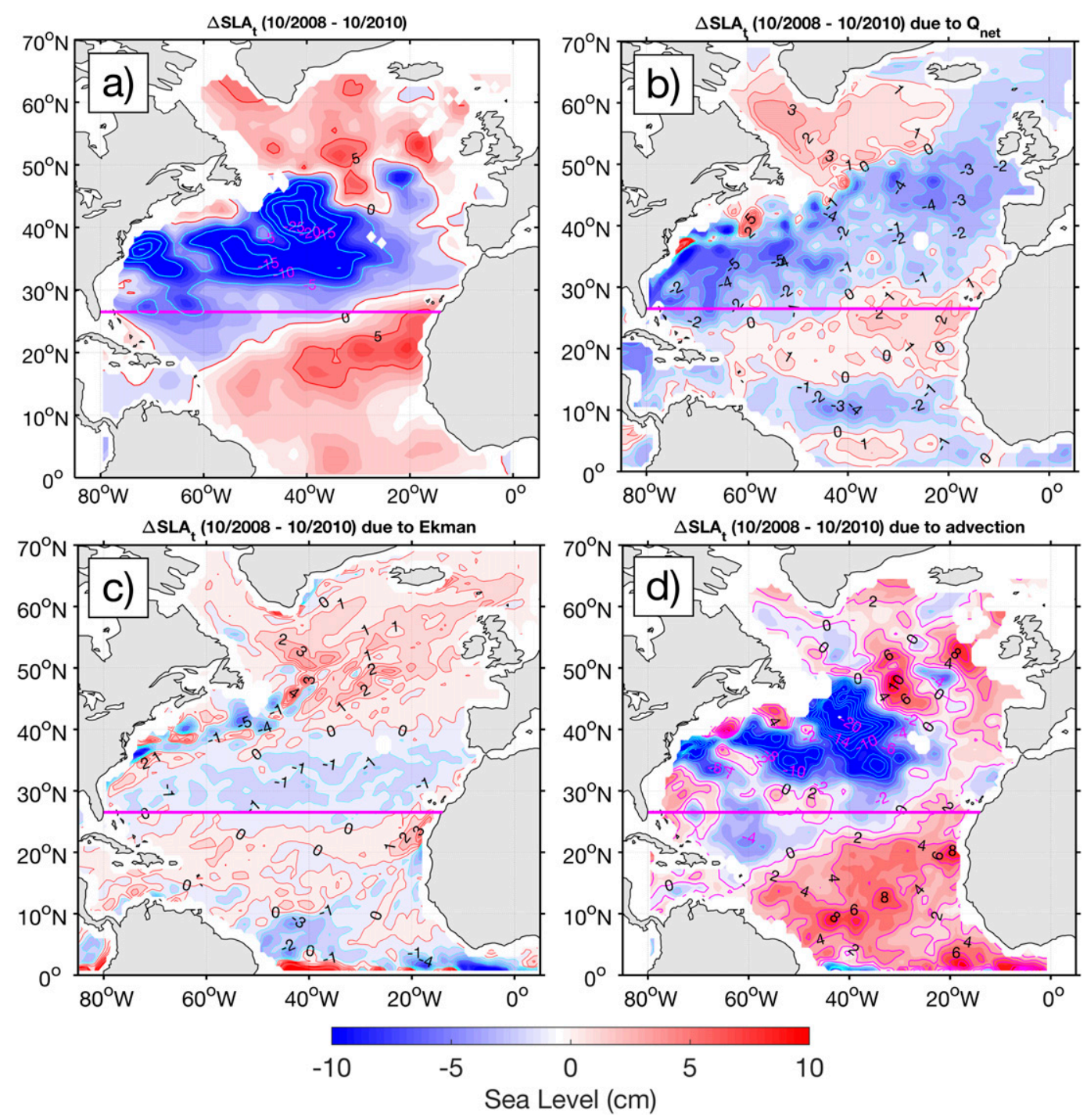

FIG. 12. (a) Thermosteric sea level change from October 2008 to October 2010 (as in Fig. 11c) and processes responsible for this change: (b) the sea level change driven by $Q_{\text {net }}$, (c) the sea level change due to the Ekman temperature advection, and (d) the residual $[=(a)-(b)-(c)]$ illustrating the contribution of advection by geostrophic currents.

shortcomings of the residual calculation, it is interesting to note that the residual provides an illustration of the likely dominance of geostrophic advection in driving the heat convergence in the equatorial-tropical band of the North Atlantic during the time interval considered, consistent with Cunningham et al. (2013) and Bryden et al. (2014). The associated sea level rise just south of the RAPID line and between October 2008 and October 2010 ranges from 4 to above $8 \mathrm{~cm}$, which is greater than the combined contribution of the air-sea heat exchange and Ekman advection. More detailed studies of this and similar events using ocean models that realistically simulate the AMOC will help to elucidate the potential role of geostrophic advection.

\section{Summary and discussion}

We have documented that from 2004 through 2016 the nearly basin-wide nonseasonal Mediterranean Sea level measured by altimetry satellites is significantly correlated with the AMOC measured by the RAPID array at about $26.5^{\circ} \mathrm{N}$ (Figs. 2, 3a). A stronger/weaker AMOC is associated with a lower/higher sea level in the Mediterranean, which was particularly pronounced during the record largest basin-mean sea level anomalies in 
2010/11 and 2013. We have shown that on the monthly time scales this correlation is mainly due to the correlation between the Mediterranean Sea level and the northward Ekman transport at $26.5^{\circ} \mathrm{N}$. The northward Ekman transport in the tropics is driven by trade winds that are part of the subtropical cell of the NAO pattern. The other two components of the AMOC, Florida Current transport $\left(T_{\mathrm{FC}}\right)$ and upper-midocean transport $\left(T_{\mathrm{UMO}}\right)$, are not correlated with the Mediterranean Sea level on monthly time scales (Table 1). Nevertheless, there is a significant lagged correlation between the Mediterranean Sea level and $T_{\mathrm{UMO}}$ at $26.5^{\circ} \mathrm{N}$ on interannual (periods greater than one year) time scales: the southward/northward anomalies of $T_{\mathrm{UMO}}$ are followed by higher/lower sea level anomalies in the Mediterranean about one year later (Fig. 5; Table 2). At the same time, the maximum correlation between the Mediterranean Sea level and Ekman transport at $26.5^{\circ} \mathrm{N}$ on interannual time scales $(r=-0.79)$ is observed at a 1-month time lag. These observations suggest that wind forcing can be a common driver for both the Mediterranean Sea level and the AMOC on monthly to interannual time scales, while the large-scale ocean circulation represented by the AMOC can affect the Mediterranean Sea level on interannual time scales. While the connection with the wind-forced Ekman component of the AMOC appears to be straightforward, the impact of large-scale ocean circulation is indirect and more complex.

The identified mechanisms responsible for the teleconnection between the Mediterranean Sea level and the AMOC are sketched in a simplified diagram in Fig. 13. We have shown that both the AMOC and the Mediterranean Sea level are related to similar gyre-scale atmospheric sea level pressure (SLP) and circulation patterns intrinsic to the NAO dipole pattern (Fig. 6). An increase/decrease of SLP in the center of the North Atlantic subtropical gyre, associated with a positive/ negative NAO phase (Figs. 13a,b, respectively), is linked with a strengthening/weakening of westerly winds in the midlatitudes and trade winds in the subtropics and tropics. The trade winds drive northward/ southward Ekman transport anomalies that directly strengthen/weaken the AMOC. Because winds over and in the vicinity of the Strait of Gibraltar are also part of the large-scale atmospheric circulation in the North Atlantic, the above changes are associated with southwestward/northeastward wind anomalies along the northwest African coast and westward/eastward wind anomalies over the Strait of Gibraltar. According to previous studies, these winds are able to modify the sea level gradient along the strait and cause barotropic sea level fluctuations in the Mediterranean (Fukumori et al.
2007; Menemenlis et al. 2007; Calafat et al. 2012; Landerer and Volkov 2013; Volkov and Landerer 2015).

Using altimetry and Argo data, we have shown that the Mediterranean Sea level is well correlated at a zero lag with sea level in the tropical band of the North Atlantic, in particular along the northwest African coast stretching toward Gibraltar (Fig. 8) in agreement with a previous modeling study by Calafat et al. (2012). This means that the AMOC, which depends on the sea level gradient across the North Atlantic and, thus, on sea level at the eastern boundary, is also related to the Mediterranean Sea level. This relationship is due to the largescale interannual sea level variability in the North Atlantic, the leading mode of which exhibits a tripole spatial pattern, with the midlatitude band varying out of phase with the equatorial-tropical and subpolar bands (Figs. 9a,b). The temporal evolution of the tripole mode is correlated with both the AMOC and the Mediterranean Sea level (Fig. 9c).

Given the dominance of the thermosteric component in the North Atlantic sea level variability, the tripole mode mainly reflects the redistribution of heat. The meridional heat transport estimated at $26.5^{\circ} \mathrm{N}$ is a good indicator of heat exchange between the midlatitude and the equatorial-tropical bands, because the RAPID/ MOCHA/WBTS observational array lies just across the boundary between the two bands. The observed heat convergence in the equatorial-tropical band with peaks in 2010 and 2013 was largely driven by the meridional heat transport across $26.5^{\circ} \mathrm{N}$. The southward anomalies of the AMOC about one year prior to these peaks, which were mainly due to the increased southward uppermidocean transport, advected heat from the North Atlantic subtropical gyre, characterized by the downward doming of isotherms as opposed to the upward doming of isotherms in the equatorial-tropical band. The associated warming and sea level rise in the equatorialtropical band extended northeastward toward the Strait of Gibraltar along the African coast and ultimately induced basin-wide changes of sea level in the Mediterranean.

During a positive/negative NAO state (Figs. 13a,b, respectively), the eastern boundary of the North Atlantic is also exposed to a surface cooling/heating anomaly. Thus, up to $25 \%-30 \%$ of the thermosteric sea level rise near the eastern boundary between $20^{\circ}$ and $25^{\circ} \mathrm{N}$ in $2008-10$ was accounted for by a surface heating anomaly (cf. Fig. 11a and Fig. 11b). At the same time, the anticyclonic/cyclonic wind anomaly favors offshore/ onshore Ekman transport near the eastern boundary that leads to a local heat divergence/convergence and strengthens/reduces the usual-for-this-region upwelling. We have shown that in 2008-10 the contribution of the 

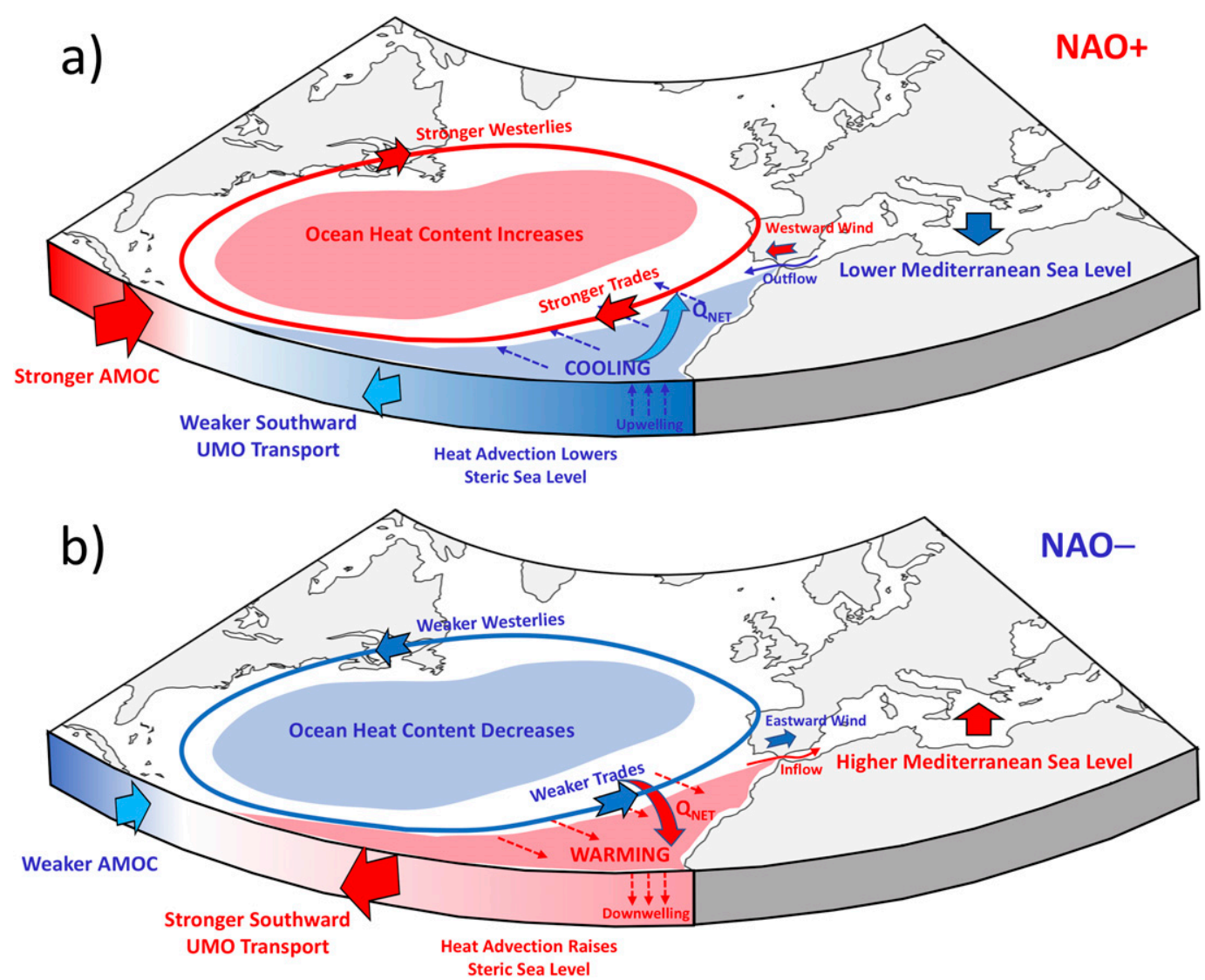

FIG. 13. Sketch summarizing the physical mechanisms linking the AMOC at $26.5^{\circ} \mathrm{N}$ and sea level in the Mediterranean Sea. A (a) positive/(b) negative NAO phase is associated with a stronger/weaker-than-average westerly and trade winds. A strengthening/weakening of the AMOC at $26.5^{\circ} \mathrm{N}$ on monthly and interannual time scales is mainly due to both (i) the direct forcing by trade winds that drive the northward/southward anomalies of $T_{\mathrm{EK}}$ and (ii) the baroclinic adjustment of the upper-ocean thermohaline structure and circulation to variable atmospheric buoyancy and momentum fluxes. First, the AMOC and the Mediterranean Sea level are linked because they are both forced by the same NAO-induced atmospheric circulation pattern. Anticyclonic/cyclonic anomalies of the subtropical atmospheric circulation drive the northward/southward $T_{\mathrm{EK}}$ anomalies at $26.5^{\circ} \mathrm{N}$, and they are associated with westward/eastward wind anomalies over the Strait of Gibraltar that pump water out of/into the Mediterranean Sea and, thus, lower/raise its sea level. Second, on interannual time scales, a positive/negative anomaly of the meridional heat transport leads to heat divergence/convergence in the equatorial-tropical band, which is associated with sea level rise that affects the northwest coast of Africa and ultimately the Mediterranean.

Ekman-induced heat advection reached up to $30 \%$ of the thermosteric sea level rise near the African coast between $20^{\circ}$ and $25^{\circ} \mathrm{N}$ (cf. Fig. 12a and Fig. 12c). As pointed out earlier, a positive/negative NAO state is also associated with westward/eastward wind anomalies over the Strait of Gibraltar that force water to flow out of/into the Mediterranean and, therefore, can amplify the remote influence of surface and lateral buoyancy fluxes in the eastern subtropical North Atlantic. Interestingly, on interannual time scales, the amplitude of the Argoderived steric sea level near the eastern boundary is about twice less than the amplitude of the altimetryderived Mediterranean Sea level. This is possibly because buoyancy fluxes in the eastern North Atlantic and winds over the Strait of Gibraltar have an equal contribution to the Mediterranean Sea level and amplify the effect of each other.

It is noteworthy that an increase/decrease of sea level near the eastern boundary changes the zonal sea level gradient across the subtropical North Atlantic and, therefore, provides a negative feedback mechanism on the AMOC changes through a reduction/ strengthening of the near-surface southward geostrophic transport, that is, the southward $T_{\mathrm{UMO}}$. The peaks of sea level in the equatorial-tropical band in 2010 and 2013 were associated with the reduction of the southward heat transport across $26.5^{\circ} \mathrm{N}$ followed by the local heat divergence and lowering of sea level in 
2011/12 and 2013-15, respectively (Fig. 9c). Such a feedback mechanism could be part of a North Atlantic self-oscillatory system.

As for any nonlinear coupled system, it is difficult to single out the process that provides the primary forcing (AMOC or atmospheric forcing in our case). As we have seen, the atmospheric forcing does directly impact the AMOC via the northward Ekman transport. However, it is necessary to note that the NAO-modulated changes in the atmospheric circulation, as reflected in the northward Ekman transport at $26.5^{\circ} \mathrm{N}$, are not necessarily coherent with changes in the large-scale geostrophic circulation. This is because the former is driven by convergence/divergence of Ekman flow and, therefore, is proportional to wind stress curl and not to wind stress. For example, $T_{\mathrm{EK}}$ and $T_{\mathrm{UMO}}$ are not correlated in 2004-07, but starting from 2008, changes in $T_{\mathrm{EK}}$ follow changes in $T_{\mathrm{UMO}}$ with about a 10 -month time lag (Fig. 5). Therefore, while it is very likely that the geostrophic part of the AMOC is wind forced (e.g., Zhao and Johns 2014), it is not a simple response to the NAO, and the mechanisms schematized in Fig. 13 are not necessarily coincident. It has been reported that a $30 \%$ reduction of the AMOC in 2008/09 was the largest contributor to the observed cooling in the upper $2 \mathrm{~km}$ of the subtropical North Atlantic, which may have pushed the atmospheric circulation into an NAO negative state in 2009/10 (Cunningham et al. 2013; Bryden et al. 2014). This illustrates a likely ocean-atmosphere feedback mechanism that may have ultimately affected the Mediterranean Sea as well.

The analysis presented in this manuscript is the first attempt to provide a comprehensive and physically consistent explanation for the observed teleconnection between the AMOC and the Mediterranean Sea level from 2004 to 2017. It should be noted, however, that while the proposed mechanism appears to be valid for this particular period, it may not hold at all times. Continued observations by the RAPID/MOCHA/WBTS array and dedicated modeling exercises are required to shed more light on the observed teleconnection.

Acknowledgments. This work was supported by the NASA Ocean Surface Topography Science Team program (via Grant NNX13AO73G) and by the National Oceanic and Atmospheric Administration (NOAA) Atlantic Oceanographic and Meteorological Laboratory, and it was carried out in part under the auspices of the Cooperative Institute of Marine and Atmospheric Studies (CIMAS) of the University of Miami and NOAA, Cooperative Agreement NA10OAR4320143. D. Smeed was supported by the EU Horizons 2020 project AtlantOs (Grant 633211). A portion of this research (F. Landerer) was carried out at the Jet Propulsion Laboratory, California Institute of Technology, under a contract with NASA. The satellite altimetry data are processed and distributed by CMEMS (http://marine.copernicus.eu). Data from the RAPIDMOC/MOCHA/WBTS MOC monitoring array are jointly funded by the U.K. Natural Environment Research Council, the National Science Foundation, and NOAA; the 12-hourly MOC data are made freely available online (www.rapid.ac.uk/rapidmoc and www. rsmas.miami.edu/users/mocha). The $26.5^{\circ} \mathrm{N}$ MOC array and Argo program are part of the Global Ocean Observing System. The Argo data were collected and made freely available by the International Argo Program and the national programs that contribute to it (http://www. argo.ucsd.edu, http://argo.jcommops.org). The monthly station-based NAO index was retrieved online (https:// climatedataguide.ucar.edu/climate-data/hurrell-northatlantic-oscillation-nao-index-station-based). The authors thank Drs. Sang-Ki Lee and Chris Hughes and an anonymous reviewer for useful comments and suggestions on the initial version of the manuscript.

\section{REFERENCES}

Andres, M., G. G. Gawarkiewicz, and J. M. Toole, 2013: Interannual sea level variability in the western North Atlantic: Regional forcing and remote response. Geophys. Res. Lett., 40, 5915-5919, https://doi.org/10.1002/2013GL058013.

Baringer, M. O., and J. C. Larsen, 2001: Sixteen years of Florida current transport at $27^{\circ} \mathrm{N}$. Geophys. Res. Lett., 28, 3179-3182, https://doi.org/10.1029/2001GL013246.

Bingham, R., and C. W. Hughes, 2009: Signature of the Atlantic meridional overturning circulation in sea level along the east coast of North America. Geophys. Res. Lett., 36, L02603, https://doi.org/10.1029/2008GL036215.

Bryden, H. L., B. A. King, G. D. McCarthy, and E. L. McDonagh, 2014: Impact of a $30 \%$ reduction in Atlantic meridional overturning during 2009-2010. Ocean Sci., 10, 683-691, https:// doi.org/10.5194/os-10-683-2014.

Buckley, M. W., and J. Marshall, 2016: Observations, inferences, and mechanisms of the Atlantic meridional overturning circulation variability: A review. Rev. Geophys., 54, 5-63, https:// doi.org/10.1002/2015RG000493.

Calafat, F. M., D. P. Chambers, and M. N. Tsimplis, 2012: Mechanisms of decadal sea level variability in the eastern North Atlantic and the Mediterranean Sea. J. Geophys. Res., 117, C09022, https://doi.org/10.1029/2012JC008285.

Cazenave, A., H.-B. Dieng, B. Meyssignac, K. von Schukmann, B. Decharme, and E. Berthier, 2014: The rate of sea-level rise. Nat. Climate Change, 4, 358-361, https://doi.org/10.1038/ nclimate2159.

Cunningham, S. A., and Coauthors, 2007: Temporal variability of the Atlantic meridional overturning circulation at $26.5^{\circ} \mathrm{N}$. Science, 317, 935-938, https://doi.org/10.1126/science.1141304. , and Coauthors, 2013: Atlantic meridional overturning circulation slowdown cooled the subtropical ocean. Geophys. Res. Lett., 40, 6202-6207, https://doi.org/10.1002/2013GL058464. 
Dee, D. P., and Coauthors, 2011: The ERA-Interim reanalysis: Configuration and performance of the data assimilation system. Quart. J. Roy. Meteor. Soc., 137, 553-597, https://doi.org/ $10.1002 /$ qj. 828 .

Delworth, T. L., and F. Zeng, 2016: The impact of the North Atlantic Oscillation on climate through its influence on the Atlantic meridional overturning circulation. J. Climate, 29, 941-962, https://doi.org/10.1175/JCLI-D-15-0396.1.

Ezer, T., L. P. Atkinson, W. B. Corlett, and J. L. Blanco, 2013: Gulf Stream's induced sea level rise and variability along the U.S. mid-Atlantic coast. J. Geophys. Res. Oceans, 118, 685-697, https://doi.org/10.1002/jgrc.20091.

Frajka-Williams, E., 2015: Estimating the Atlantic overturning at $26^{\circ} \mathrm{N}$ using satellite altimetry and cable measurements. Geophys. Res. Lett., 42, 3458-3464, https://doi.org/10.1002/2015GL063220.

— flow components of the Atlantic MOC at $26^{\circ}$ N. Ocean Sci., 12, 481-493, https://doi.org/10.5194/os-12-481-2016.

Fukumori, I., D. Menemenlis, and T. Lee, 2007: A near-uniform basin-wide sea level fluctuation of the Mediterranean Sea. J. Phys. Oceanogr., 37, 338-358, https://doi.org/10.1175/ JPO3016.1.

Gill, A. E., 1982: Atmosphere-Ocean Dynamics. Academic Press, $662 \mathrm{pp}$.

Goddard, P. B., J. Yin, S. M. Griffies, and S. Zhang, 2015: An extreme event of sea-level rise along the northeast coast of North America in 2009-2010. Nat. Commun., 6, 6346, https://doi.org/ $10.1038 /$ ncomms 7346.

Grinsted, A., J. C. Moore, and S. Jevrejeva, 2004: Application of the cross wavelet transform and wavelet coherence to geophysical time series. Nonlinear Processes Geophys., 11, 561-566, https://doi.org/10.5194/npg-11-561-2004.

Hall, M. M., and H. L. Bryden, 1982: Direct estimates and mechanisms of ocean heat transport. Deep-Sea Res., 29A, 339-359, https://doi.org/10.1016/0198-0149(82)90099-1.

Hosoda, S., T. Ohira, and T. Nakamura, 2008: A monthly mean dataset of global oceanic temperature and salinity derived from Argo float observations. JAMSTEC Rep. Res. Dev., 8, 47-59, https://doi.org/10.5918/jamstecr.8.47.

Hurrell, J. W., Y. Kushnir, G. Ottersen, M. Visbeck, 2003: An overview of the North Atlantic Oscillation. The North Atlantic Oscillation: Climate Significance and Environmental Impact, Geophys. Monogr., Vol. 134, Amer. Geophys. Union, 1-35, https://doi.org/10.1029/134GM01.

Johns, W. E., T. Kanzow, and R. Zantopp, 2005: Estimating ocean transports with dynamic height moorings: An application in the Atlantic deep western boundary current at $26^{\circ}$ N. Deep-Sea Res. I, 52, 1542-1567, https://doi.org/10.1016/j.dsr.2005.02.002.

— Atlantic Ocean heat transport at $26.5^{\circ} \mathrm{N}$. J. Climate, 24, 2429-2449, https://doi.org/10.1175/2010JCLI3997.1.

Landerer, F. W., and D. L. Volkov, 2013: The anatomy of recent large sea level fluctuations in the Mediterranean Sea. Geophys. Res. Lett., 40, 553-557, https://doi.org/10.1002/grl.50140.

- D. N. Wiese, K. Bentel, C. Boening, and M. M. Watkins, 2015: North Atlantic meridional overturning circulation variations from GRACE ocean bottom pressure anomalies. Geophys. Res. Lett., 42, 8114-8121, https://doi.org/10.1002/ 2015 GL065730.

Levermann, A., A. Griesel, M. Hofmann, M. Montoya, and S. Rahmstorf, 2005: Dynamic sea level changes following changes in the thermohaline circulation. Climate Dyn., 24, 347-354, https://doi.org/10.1007/s00382-004-0505-y.
Little, C. M., C. G. Piecuch, and R. M. Ponte, 2017: On the relationship between the meridional overturning circulation, alongshore wind stress, and United States East Coast sea level in the Community Earth System Model Large Ensemble. J. Geophys. Res. Oceans, 122, 4554-4568, https://doi.org/ 10.1002/2017JC012713.

Marshall, J., H. Johnson, and J. Goodman, 2001: A study of the interaction of the North Atlantic Oscillation with ocean circulation. J. Climate, 14, 1399-1421, https://doi.org/10.1175/ 1520-0442(2001)014<1399:ASOTIO>2.0.CO;2.

McCarthy, G. D., and Coauthors, 2012: Observed interannual variability of the Atlantic meridional overturning circulation at $26.5^{\circ}$ N. Geophys. Res. Lett., 39, L19609, https://doi.org/ 10.1029/2012GL052933.

_ - and Coauthors, 2015a: Measuring the Atlantic meridional overturning circulation at $26^{\circ}$ N. Prog. Oceanogr., 130, 91-111, https://doi.org/10.1016/j.pocean.2014.10.006.

— I. D. Haigh, J. J.-M. Hirschi, J. P. Grist, and D. A. Smeed, 2015b: Ocean impact on decadal Atlantic climate variability revealed by sea-level observations. Nature, 521, 508-512, https://doi.org/10.1038/nature14491.

Menemenlis, D., I. Fukumori, and T. Lee, 2007: Atlantic to Mediterranean sea level difference driven by winds near Gibraltar Strait. J. Phys. Oceanogr., 37, 359-376, https://doi.org/10.1175/ JPO3015.1.

Piecuch, C. G., and R. M. Ponte, 2014: Nonseasonal mass fluctuations in the midlatitude North Atlantic Ocean. Geophys. Res. Lett., 41, 4261-4269, https://doi.org/10.1002/2014GL060248.

Poli, P., and Coauthors, 2013: The data assimilation system and initial performance evaluation of the ECMWF pilot reanalysis of the 20th-century assimilating surface observations only (ERA-20C). ECMWF Tech. Rep. 14, 59 pp.

Pujol, M.-I., Y. Faugère, G. Taburet, S. Dupuy, C. Pelloquin, M. Ablain, and N. Picot, 2016: DUACS DT2014: The new multi-mission altimeter data set reprocessed over 20 years. Ocean Sci., 12, 1067-1090, https://doi.org/10.5194/os-12-10672016.

Rayner, D., and Coauthors, 2011: Monitoring the Atlantic meridional overturning circulation. Deep-Sea Res. II, 58, 1744-1753, https://doi.org/10.1016/j.dsr2.2010.10.056.

Smeed, D., G. McCarthy, D. Rayner, B. I. Moat, W. E. Johns, M. O. Baringer, and C. S. Meinen, 2017: Atlantic meridional overturning circulation observed by the RAPID-MOCHA-WBTS (RAPID-Meridional Overturning Circulation and Heatflux Array-Western Boundary Time Series) array at 26N from 2004 to 2015. British Oceanographic Data CentreNatural Environment Research Council, accessed 8 October 2015, https://doi.org/10.5285/5acfd143-1104-7b58e053-6c86abc0d94b.

Smith, R. L., 1978: Poleward propagating perturbations in currents and sea levels along the Peru coast. J. Geophys. Res., 83, 60836092, https://doi.org/10.1029/JC083iC12p06083.

Srokosz, M. A., and H. L. Bryden, 2015: Observing the Atlantic meridional overturning circulation yields a decade of inevitable surprises. Science, 348, 1255575, https://doi.org/ 10.1126/science.1255575.

Stepanov, V. N., and K. Haines, 2014: Mechanisms of Atlantic meridional overturning circulation variability simulated by the NEMO model. Ocean Sci., 10, 645-656, https://doi.org/ 10.5194/os-10-645-2014.

Sutton, R. T., and D. L. R. Hodson, 2005: Atlantic Ocean forcing of North American and European summer climate. Science, 309, 115-118, https://doi.org/10.1126/science.1109496. 
Trenberth, K. E., and J. M. Caron, 2001: Estimates of meridional atmosphere and ocean heat transports. J. Climate, 14, 3433-3443, https://doi.org/10.1175/1520-0442(2001)014<3433: EOMAAO $>2.0 . \mathrm{CO} ; 2$.

Tsimplis, M. N., and S. A. Josey, 2001: Forcing of the Mediterranean Sea by atmospheric oscillations over the North Atlantic. Geophys. Res. Lett., 28, 803-806, https://doi.org/10.1029/ 2000 GL012098.

—_, and M. Rixen, 2002: Sea level in the Mediterranean Sea: The contribution of temperature and salinity changes. Geophys. Res. Lett., 29, 2136, https://doi.org/10.1029/2002GL015870.

_ and A. G. P. Shaw, 2008: The forcing of mean sea level variability around Europe. Global Planet. Change, 63, 196-202, https://doi.org/10.1016/j.gloplacha.2007.08.018.

— E. Álvarez-Fanjul, D. Gomis, L. Fenoglio-Marc, and B. Pérez, 2005: Mediterranean Sea level trends: Atmospheric pressure and wind contribution. Geophys. Res. Lett., 32, L20602, https:// doi.org/10.1029/2005GL023867.

—_, M. Marcos, S. Somot, and B. Barnier, 2008: Sea level forcing in the Mediterranean Sea between 1960 and 2000. Global Planet. Change, 63, 325-332, https://doi.org/10.1016/j. gloplacha.2008.07.004.

- and Coauthors, 2013: The effect of the NAO on sea level and on mass changes in the Mediterranean Sea. J. Geophys. Res. Oceans, 118, 944-952, https://doi.org/10.1002/jgrc.20078.
Volkov, D. L., and L.-L. Fu, 2011: Interannual variability of the Azores Current strength and eddy energy in relation to atmospheric forcing. J. Geophys. Res., 116, C11011, https:// doi.org/10.1029/2011JC007271.

, and F. W. Landerer, 2015: Internal and external forcing of sea level variability in the Black Sea. Climate Dyn., 45, 2633-2646, https://doi.org/10.1007/s00382-015-2498-0.

von Storch, H., and F. W. Zwiers, 1999: Statistical Analysis in Climate Research. Cambridge University Press, $484 \mathrm{pp}$.

Wang, C., and L. Zhang, 2013: Multidecadal ocean temperature and salinity variability in the tropical North Atlantic: Linking with the AMO, AMOC, and subtropical cell. J. Climate, 26, 6137-6162, https://doi.org/10.1175/JCLI-D-12-00721.1.

Woodworth, P. L., M. Á. M. Maqueda, V. M. Roussenov, R. G. Williams, and C. W. Hughes, 2014: Mean sea-level variability along the Northeast American Atlantic coast and the roles of the wind and the overturning circulation. J. Geophys. Res. Oceans, 119, 8916-8935, https://doi.org/10.1002/2014JC010520.

Yin, J., and P. B. Goddard, 2013: Oceanic control of sea level rise patterns along the East Coast of the United States. Geophys. Res. Lett., 40, 5514-5520, https://doi.org/10.1002/2013GL057992.

Zhao, J., and W. Johns, 2014: Wind-forced interannual variability of the Atlantic meridional overturning circulation at $26.5^{\circ} \mathrm{N}$. J. Geophys. Res. Oceans, 119, 2403-2419, https://doi.org/ 10.1002/2013JC009407. 